NBER WORKING PAPER SERIES

WHAT HAPPENED DURING THE BABY BOOM?

NEW ESTIMATES OF AGE- AND PARITY-SPECIFIC

BIRTH PEOBABILITIES POR AKERICAN WOMEN

Warren Sanderson

Working Paper No. 23

CENTER FOR ECONOMIC ANAIYSIS OF IIUMAN BEHAVIOR $\Lambda$ ND SOCIAL INSTITUTIONS National Bureau of Economic Research, Inc. 261 Madison Avenue, New York, N.Y. 10016

December, 1973

Preliminary; Not for Quotation

NBER working papers are distributed informally and in limited number for coments only. They should not be quoted without written permission.

This report has not undergone the review accorded officlal NBER publications; in particular, it has not yet been subritted for approval by the Board of Directors.

The research reported herein was performed pursuant to grants from the Ford Foundation and from the National Institute of Child Health and Human Development, National Institutes of Health (U.S. Dept. of Health, Education, and Welfare). The opinions expressed herein are those of the author and do not necessarily reflect the views of the grantors. 


\section{WHAT HAPPENED DURING THE BABY BOOM? NEW ESTIMATES OF AGE-AND PARITY- SPECIFIC BIRTH PROBABILITIES \\ FOR AMERICAN WOMEN}

\section{by}

Warren C, Sanderson

-Stanford Untversity

The baby boom is over and, with fertility in the United States currently below replacement level, it may well be said that a birth dearth is already upon us. Graph 1 shows the U, S, general fertility rate ${ }^{1}$ from 1909 through $1968 .^{2}$ The secular movement of this rate is clearly downward. However, this secular decline was interrupted by a period in the $1950^{\prime}$ 's when fertility was both relatively high and increasing. The peak general fertility rate during the baby boom occurred in 1957 and subsequently fertility has fallen every year thereafter with the exceptions of 1969 and $1970,^{3}$ This recent fertility history presents a problem for economists and other interested in fertility. Is the current low level of fertility but a trough in a long cycle which is destined to produce yet another baby boom or is it a manifestation of a continued secular decline in fertility? To put the same problem in somewhat different terms: is a baby boom an anomolous or systematic phenomenon.

Although in recent years, there have been important advances in the economic theory of fertility, ${ }^{4}$ these contributions have not yet been sufficiently articulated to throw much light on the course of 
postwar fertility changes. It is the main purpose of this paper to examine in detail the pattern of fertility fluctuations in the United States since the Second World War and to define, with some prectsion, the questions these patterns raise for students of fertility behavior. Towards this end I present new estimates of age- and parity-specific monthly birth probabilities for cohorts of native white women born in the twentieth century. These data lend themselves to numerous uses; only one of which is pursued here-me close analysis of the structure of fertility changes after 1950. What they reveal in that connection are hitherto unrecognized patterns of fertility variation across age and parity groups during the baby boom. Perhaps the most startling finding is that, although aggregate fertility measures reach their "baby boom" peak in 1957, the birth probabilities often do not. Looking across groups of women of different ages one finds that probabilities of second and higher order births reached a peak leyel during the years $1953-1955$ as frequently as in the years 1956-1958. The probabilities of second through fourth order births for young women consistently reached their peak during the period 1959-1961. In addition, the new data pertaining to lower order births show that before the Second World War temporal variations in birth probabilities were quite similar across age groups. After the War, that is to say during the height of the Baby Boom, a marked structural change occurred and the positive correlation across age groups disappeared, To aid further analysis of the mass of birth probability data, I have "decomposed" the time series for different birth orders into an 
"age", a "current year", and a "cohort" component. For each of the birth orders, this trio of components allows us to disentangle the distinct influences which intertwined themselves, giving rise to the observed birth probabilities. This analysis shows that the cohort influences were very important in creating the pattern of first birth probability fluctuations in the baby boom period. The strength of this source of influence progressively diminished in the case of higher order births, however. The current year components for first birth probabilities exhibit a time profile which is unlike those for higher order births in that its peak precedes 1957 while the peaks of the current year components for higher order births all occur in 1957. In view of the absence of uniformity in the temporal patterns exhibited by the varlous birth probability series, it may be reassuring to note that the famillar movement to a 1957 peak does emerge in the current year components for each of the birth orders save the first.

While the behavior of the current year components by themselves would have promoted a cyclical swing in aggregate fertility paralleling the one in the postwar perfod, the amplitude of that movement would have been much smaller. Since the current year effects had to work against the anti-natal influence of the changing age structure of the population, were it not for the "cohort" influence already noticed the outcome may not even have qualified as the "Baby Bubble" much less the "Baby Boom". 


\section{Birth Probabilities.}

Patterns of fertility variations will be analyzed, in this study, using data, estimated by the author, on age- and parity-specific birth probabilities for cohorts of native white women born after 1899 . Birth probabilities were first measured for the United States by Whelpton in his pioneering book, Cohort Fertility, published in 1954. There Whelpton presented annual age- and parity-specific birth probabilities for native white women for the years 1920 through $1950 .^{6}$ Whelpton's original work spawned further efforts at measuring birth probabilities ${ }^{7}$ and birth probabilities for all U. S. women are now regularly published in Vital Statistics of the United States. Since the first year for which these data are reported is 1956 those interested in the behavior of time series fertility measures are left in something of a quandry. There is one study on birth probabilities of native. white women for the years 1920 through 1950 using one methodology and another for all U. S. women covering the period 1956-1968 using a somewhat different methodology. In order to facilitate the interpretation of time series trends it is preferable to study the birth probabilities of native white women rather than those of all U. S. women and so, with an improved methodology, ${ }^{8}$ I have re-estimated some of Whelpton's birth probabilities for native white women and extended his series through $1966 .^{9}$

Annual age- and parity-specific birth probabilities are of interest for a number of reasons. Chief among their attractions is that a birth probability is a period fertility measure which is consistent with economic decisionmaking models of fertility. It is implausible to think of the total fertility rate or the net reproduction rate as being the outcome of a household decisionmaking process. However, birth probabilities may, quite plausibly, be considered as outcome of such a process as Michael (1973) has already demonstrated. 
Another attraction of the birth probability data used in this paper is that they allow the investigator to follow cohorts of women over their life cycles and study the processes through which their completed family sizes are attained. Also, birth probabilities, particularly monthly birth probabilities like those presented here, are parameters in mathematical models of fertility and contraception developed by demographers. 10

Conceptually, an age- and parity-specific monthly birth probability is a rather simple affair, Let us consider, for example, a highly simplified computation of the monthly birth probability of thirty year old native white women who have had exactly two previous births having a third birth in 1960. This particular monthly probability is, by the way, about 1.2 percent or on an annual basis about 13.8 percent. For ease of exposition, let us assume that all these women were born on January 1, 1930, so that each of them spends the full twelve months in which she is 30 in the calendar year 1960. In addition, let us assume that all of these women had their second births before they were 29 (i.e. before the calendar year 1959). If we were to consider the possibility of second births occurring in 1959, in this simplified example, then the women who had had such births would not be, on the average, at risk of having a third child for a full twelve months in 1960. Neglecting mortality, we may write:

$$
\text { (1) } \quad B=N-N(1-p)^{12}
$$

where $B$ is the number of third births to 30 year old native white women in 1960 , N is the number of 30 year old native white women who are capable 
of having a third birth at the beginning of 1960, and $p$ is the monthly birth probability we are seeking. From Equation 1, it may be readily seen that:

$$
\text { (2) } \quad \mathrm{p}=1-\left(\frac{\mathrm{N}-\mathrm{B}}{\mathrm{N}}\right)^{1 / 12} \text {. }
$$

The two major components of all birth probabilities are data on ageand parity-specific births and age- and parity-specific numbers of women at risk of having a birth.

When monthly birth probabilities are actually computed, we cannot take for granted that all women are born on January 1st, nor that al1 previous births have occurred sufficiently long before the period of interest that current birth risk status is unaffected, nor can mortality be neglected. In addition, in estimating birth probabilities we must obtain data on births by parity and single years of age for native white women, and estimates of women capable of having a birth of a given order, aggregated according to whether they have had their last birth more than one year ${ }^{11}$ before the period of interest or not. - When these complications are added to the computation, the birth probabilities can no longer be calculated directly and must obtained using an iterative procedure. This procedure is discussed in more detail in Appendix I. Looking at the aggregated birth probabilttles presented in Appendix II and the underlying disaggregated birth probabilities, one can see what is a rather remarkable fact: birth probabilities of ten do not 
have their baby boom peak ${ }^{12}$ In 1957. Table 1 sumarizes data on the year in which our 205 age- and parity-specific birth probability acries $^{13}$ have their baby boom peaks. Out of the 205 series, 43 or about 21 percent of them peak in 1957, and 70, or about 34 percent of them peak In the period 1956-1958.

Table 1: Number of Birth Probability Series Peaking Within the Given Time Interval.

\begin{tabular}{ccccccccc|c|c|}
\hline Years & \multicolumn{7}{c|}{ Birth Orders } & \multirow{2}{*}{ Total } \\
\hline $1950-1952$ & 1st & 2nd & 3 rd & 4 th & 5 th & 6 th & 7 th & 8 th + & Tot \\
$1953-1955$ & 3 & 4 & 0 & 0 & 8 & 3 & 1 & 9 & 32 \\
$1956-1958$ & 15 & 7 & 7 & 7 & 7 & 12 & 10 & 5 & 70 \\
$(1957)$ & $(15)$ & $(4)$ & $(4)$ & $(4)$ & $(4)$ & $(5)$ & $(5)$ & $(2)$ & $(43)$ \\
$1959-1961$ & 3 & 13 & 12 & 9 & 0 & 1 & 1 & 2 & 41 \\
$1962-1966$ & 3 & 0 & 1 & 0 & 0 & 0 & 0 & 0 & 4 \\
Total & 30 & 29 & 28 & 27 & 25 & 24 & 22 & 20 & 205 \\
\hline
\end{tabular}

Source: Sanderson (1974).

It is clear from Table 1 that the 1957 peak was most common for first births. In fact, if we consider only second and higher order births, we find that the same number of sertes peak in 1953-1955 as do in 1956-1958. It is also Interesting to note with regard to Table 1 that peaks occurring after the B56-1958 period are not common except for second, third, and fourth order b1rths. The observation that birth probabilities do not generally peak in 1957 suggests the important question: what regularities, if any, exist in the post-war movements of birth probabilities. 
One important and striking regularity in the pattern of birth probabilities is shown by the first birth probabilities of women 27 years old and younger. All the first birth probabilities of women 15 through 27 years old rise in the 'fifties to a peak in 1957 . These ages account for 13 of the 15 first birth probability series which peak in 1957. The other series which peak in 1957 do so more or less unsystematically. For example, the four ages for which there are peaks in third order birth probabilities in 1957 are 31, 32, 43, and 44 and the five ages in which there are peaks in sixth order birth probabilities are $31,36,37$, 41, and 43. Thus, the first birth probabilities of women 27 and under form the only coherent set of birth probabilities which peak in the same year as the crude birth rate. ${ }^{14}$ The timing of the fluctuations of these first birth probabilities was an important determinant of the timing of the baby boom fertility peak. Although in 1957 first births to native white women 15 to 27 accounted for only about 25 percent of all births to these women, the decline in the first births to women 15 to 27 accounted for about 50 percent of the decline in all births from 1957 to 1958.

As can be seen from Appendix Graph I-I in Appendix II, the fact that first birth probabilities for young women tended to peak in the same year as the crude birth rate does not mean that their patterns of change in the 'fifties were similar to one another. By 1957, the first birth probabilities for women 15 to 19 years of age had increased about 31 percent over their 1950 level, those of women 20 to 24 had increased about 38 percent over their 1950 level, but those of women 25 to 29 increased to only 10 percent above their 1950 level. The first birth probabilities of women 15 to 19 fell somewhat more rapidly from its peak than the first birth 


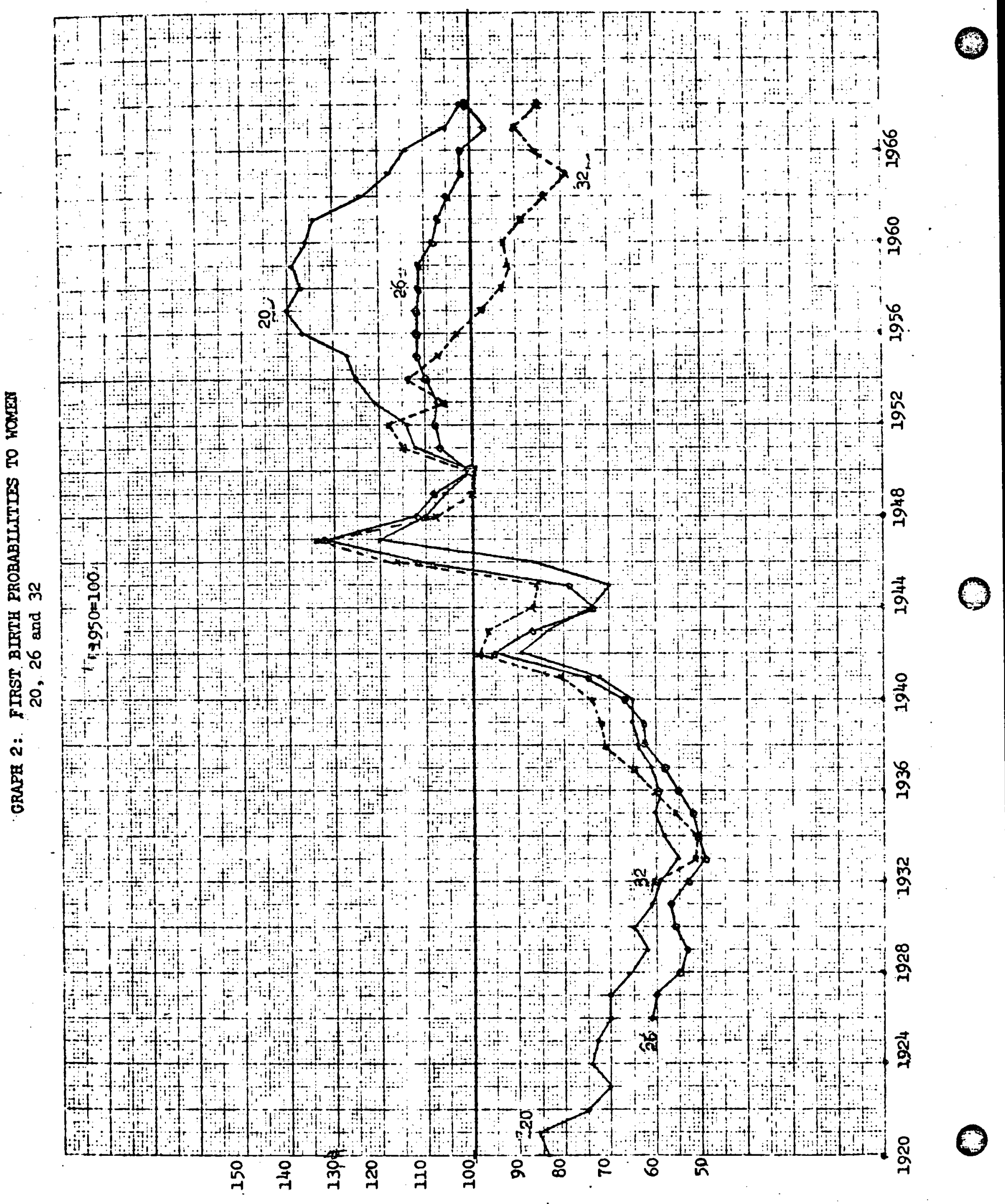


probabilities of women 20 to 24 and the first birth probabilities of women 25 to 29 fell the least.

The first birth probabilities for women over 27 years old behaved quite differently in the postwar period from those of their younger sisters. It can be seen from Appendix Graph I-2 that the first birth probabilities of women in the 30-34, 35-39, and 40-44 year old age groups began to fall in the 'fifties before 1957. The differences in the behavior of the first birth probabilities of women of different ages can be clearly seen in Graph 2, where we have plotted the first birth probabilities of women aged 20, 26, and 32. This graph shows that, although before World War II the first birth probabilities of these women tended to move similarly, in the postwar period their first birth probabilities show a rather remarkable divergence. This considerable dissimilarity of the patterns of change of first birth probabilities by age groups is an important feature of the baby boom and any thorough explanation of postwar fertility variations must come to grips with it. We shall return to this question later in the paper.

Second birth probabilities to women 16-19, 20-24, and 25-29 are plotted in Appendix Graph II-1. All three age groups show a substantial increase in their second birth probabilities over the course of the 'fifties. However, unlike the first birth probabilities of women of the same ages, the second birth probabilities do not reach their maximum in 1957, but rather in 1960 or 1961 . Thus the baby boom peaks in second birth probabilities for these women lag their first birth probability peaks by about three years. Another interesting aspect of this graph is the difference in the patterns of first and second birth probabilities to women 25 to 29 years. 
The first birth probabilities of these women are almost constant from 1951 through 1956, but during the same period their second birth probabllities rise by about 25 percent. This difference in the behavior of first and second birth probabilities during the baby boom raises another interesting question and we shall also return to it below.

Appendix Graph II-2 shows the second birth probabilities of women $30-34,35-39,40-44$. Like the first birth probabilities of these women and in sharp contrast with the second birth probabilities of younger women, the second birth probabilities of these women tend to peak before 1957. The baby boom peak of second birth probabilities to 30-34 year olds lags the peak of first birth probabilities by two years, but the peaks of first and second birth probabilities to women 35-39 and 40-44 occur in the same year.

It can be seen from Appendix Graphs III-1 and III-2 that the patterrs of third birth probabilties appear to be similar to those of second birth probabilities. Third birth probabilities for women below 30 tend to peak around 1960 and third birth probabilities for women 35-39 and 40-44 tend to peak before 1957. In this case, third birth probabilities for women 30-34 peak in 1957. In fact, as can be seen from Graph 3, as we move from first through third births the time profile of birth probabilities of 30-34 year old women looks more like the time profiles for younger women.

Although the fourth birth probabilities of women 20-24 peak In 1961 and those for women 25-29 in 1960, their rise over the decade of the 'fifties is considerably smaller than the lower order birth probabilities of women the same age. For example, third order birth probabilities 


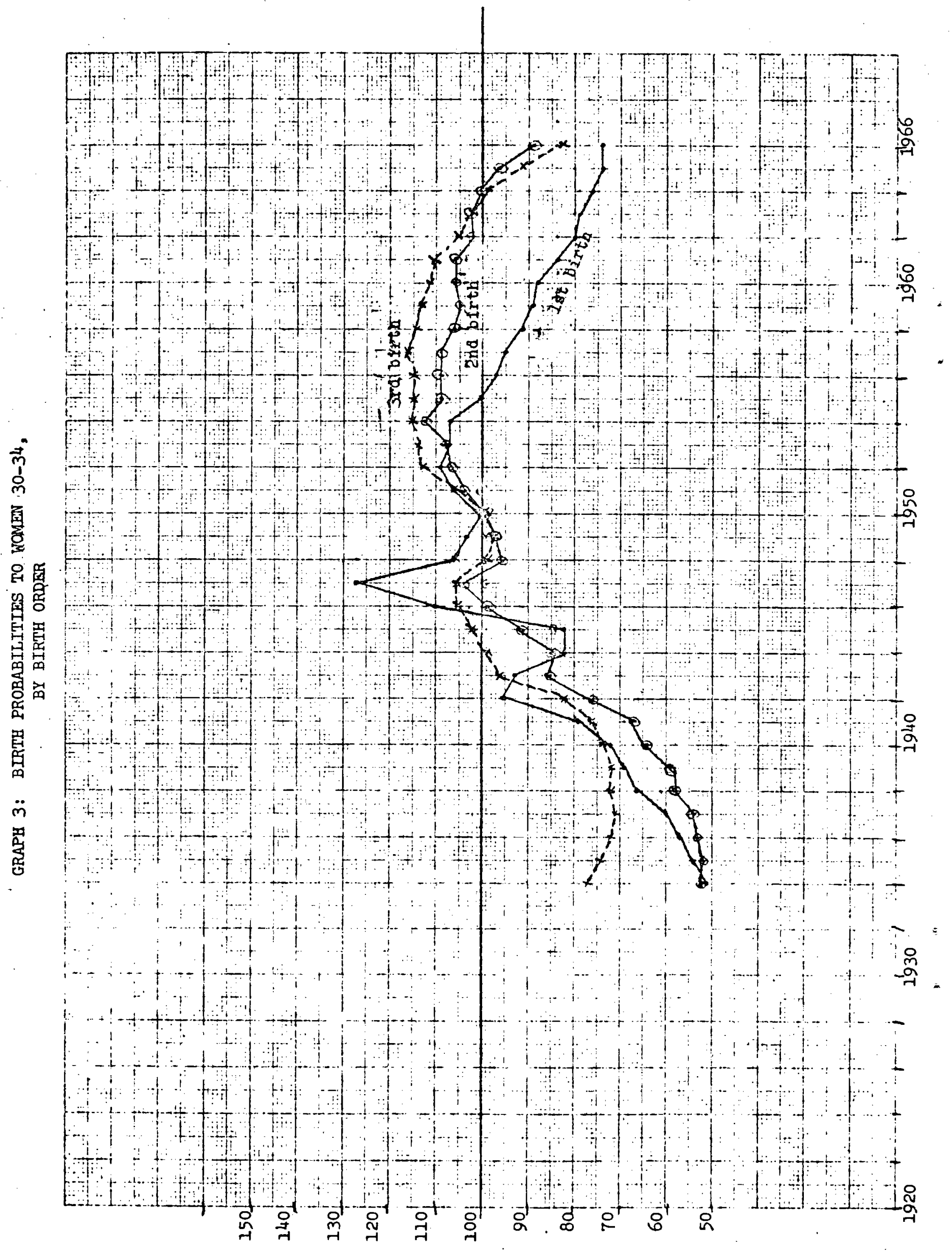


for women 20-24 rose over 30 percent from 1950 to 1960 , whereas fourth birth probabilities to these women rose less than 7 percent. during the decade. For women 25-29 the rise in third birth probabliltles was about 33 percent and for fourth birth probabilties only about 15 percent. The fourth birth probabilities for women over 30 rose more rapidly in the first half of the baby boom decade than the fourth birth probabilities of younger women. Indeed, as a practical matter It appears that the fourth birth.probabilities of women $30-34$ and 40-44 peaked in 1957.15

With fifth and higher order births, post-1957 peaks in the aggregated birth probabilities presented in Appendix II disappear and the age patterns of the birth probabilities become somewhat less regular. The fifth birth probabilities for women 25-29 peak in 1952, their sixth probabilities in 1953, their seventh birth probabilities in 1954, and their eighth and higher birth probabilities in 1956. The fifth, sixth and seventh birth probabilities for women 30-34 peak in 1956, and the eighth-plus birth probabilities peak a year later. 
Component Analysis.

We have seen above that fertility behavior in the postwar period was far from being uniform. All birth probabilities did not rise in the 'fifties to a peak in 1957 and decline thereafter, but rather they showed a number of different patterns. How are we to understand these patterns? In order to make some sense out of the multiplicity of fertility series, we must introduce at least a modicum of analytic structure. In this.pursuit, we shall posit the following representation of birth probabilities:

$$
\ln \left(p_{i j k l}\right)=\alpha_{i \ell}+\beta_{j \ell}+\gamma_{k \ell}+\varepsilon_{i j k \ell}
$$

where $\mathrm{p}_{i j k l}$ is the monthly birth probability of birth order $\ell$ for women of age $i$ in year $j$, (the index $k$ represents the year in which these women were born and can be derived from a knowledge of $i$ and $j$ ), $\alpha_{i l}$ is the age component, $\beta_{j l}$ is the current year component, $\gamma_{k \ell}$ is the cohort component, and $\varepsilon_{i j k l}$ is a random disturbance term assumed to be independently normally distributed with mean zero and cohort variance

This is a rather broad decomposition because we do not need to know precisely what the current year or cohort influences on birth probabilities of a given order are in order to measure their contribution to variations in birth probabilities. The decomposition proposed here is roughly in the spirit of Easterlin's analysis. In his article on the baby boom in historical perspective, ${ }^{16}$ he explains the fertility variations of native white urban women using variations in the unemployment rate and 
changes in the rate of growth of the size of the group of males 20 to 29 years of age. The influence in the first of these factors would be recorded as variation in the current year component in the proposed decomposition, and the latter, since it is a reflection of relative cohort size, would be recorded as variation in the cohort component. The Easterlin-Fuchs intergenerational relative income hypothes is ${ }^{17}$ may also be easily represented in our proposed framework because parental income levels, in as much as they affect tastes, are likely to have influences which remain with cohorts throughout their whole reproductive span, and therefore influences which can be captured as changes in cohort components. The suggested decomposition, broadens somewhat the Easterlin hypotheses since separate age, current year, and cohort components are estimated for each birth order. Separate cohort components, for example, allow for the intergenerational relative income effect, if it is present, to affect the birth probabilities differently for different birth orders. However, along with certain advantages, the birth probability decomposition in Equation 3 has certain disadvantages. One has to do with the Interaction between cohort and current year components. Given the specification in Equation 3, temporal patterns of birth probabilities of women of differing ages, parity held constant; are allowed to differ only because of the variations in the cohort components. Thus certain sorts of influences on fertility may not be correctly captured in this analysis. The influence of veteran's benefits after World War II may be one of these. We do not maintain the total absence of such influences on fertility, but rather that they ae of minor Importance compared with those influences which are correctly measured. 
Another disadvantage of the proposed decomposition is the econometric difficulty of thoroughly disentangling the age, current year and cohort components. We can rewrite Equation 3 as follows:

$$
\text { (4) } \quad\left[\operatorname{lnp}_{\ell}\right]=\sum_{r=A^{*}}^{A^{* *}} \alpha_{r \ell}\left[A_{r}\right]+\sum_{s=Y^{*}}^{Y * *} B_{s l}\left[Y_{s}\right]+\sum_{t=C^{*}}^{C^{* *}} \gamma_{t \ell}\left[C_{t}\right]+[\varepsilon]
$$

where $\left[1 n p_{\ell}\right]$ is a column vector of observations on the natural logarithms of birth probabilities of order $\ell$, its general element being $\ln \left(\mathrm{P}_{\mathbf{i j k} \ell}\right)$, where $\left[A_{r}\right]$ is a dumny variable vector which is unity if the age referred to in the corresponding element of the observation vector is $r$ and zero otherwise,

where $\left[\mathrm{Y}_{\mathrm{S}}\right]$ is a dummy variable vector which is unity if the year referred to in the corresponding element of the observation vector is year $s$ and zero otherwise,

where $\left[C_{t}\right]$ is a dummy variable vector which is unity if the cohort referred to in the corresponding element of the observation vector is $t$, and zero otherwise, where $[\varepsilon]$ is a vector of random numbers assurea to be generated independently from a normal distribution with mean zero, and constant variance, and where $A^{*}$, and $A^{* *}$ represent the first and last ages used in the analysis, and $Y^{*}$ and $Y^{* *}$, and $C *$ and $C * *$ have similar meanings for current years and for cohorts.

Equation 4 cannot be estimated directly because of linear dependencies between the age, current year, and cohort dumbies. Indeed, since an age and a cohort are associated with each observation we must have: 
(5)

$$
\sum_{r=A^{*}}^{A^{* *}}\left[A_{r}\right]=\sum_{t=C *}^{C * *}\left[C_{t}\right]
$$

Therefore, we can write:

(6)

$$
\left[A_{j}\right]=\sum_{t=C *}^{C * *}\left[C_{t}\right]-\sum_{\substack{r=A^{*} \\ r \neq j}}^{A * *}\left[A_{r}\right]
$$

Substituting Equation 6 into Equation 4, we obtain:

$$
\text { (7) }\left[\operatorname{lnp}_{\ell}\right]=\sum_{\substack{r=A^{*} \\ r \neq j}}^{A * *}\left(\alpha_{r \ell}-\alpha_{j \ell}\right)\left[A_{r}\right]+\sum_{s=Y *}^{Y * *} B_{s \ell}\left[Y_{s}\right]+\sum_{t=C *}^{C * *}\left(Y_{t \ell}+\alpha_{j \ell}\right)\left[C_{t}\right]+[\varepsilon]
$$

However, since each observation is associated with a current year and a cohort component, we must have:

(8) $\quad \sum_{s=Y *}^{Y * *}\left[Y_{s}\right]=\sum_{t=C *}^{C * *}\left[C_{t}\right]$.

Therefore, we can write:

(9) $\quad\left[Y_{k}\right]=\sum_{t=C *}^{C * *}\left[C_{t}\right]-\sum_{\substack{s=Y * \\ s \neq k}}^{Y * *}\left[Y_{s}\right]$

Substituting Equation 9 into Equation 7 we obtain

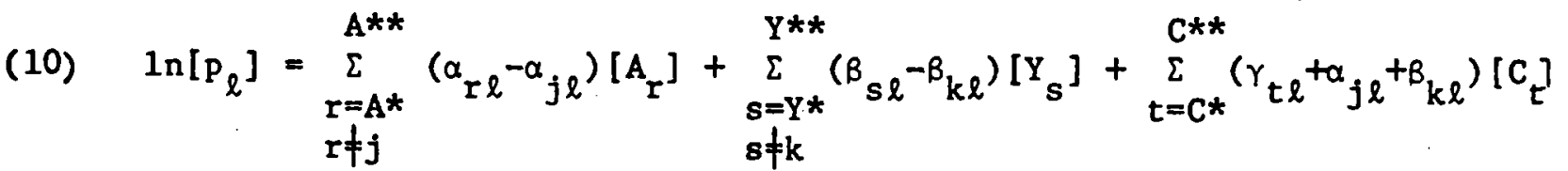

$$
\begin{aligned}
& +[\varepsilon]
\end{aligned}
$$

There is one more linear dependency in the remaining dumm variable vectors.

A person who is of age $j$ in year $k$ was born in year $k-j$, which we call year $m$. The linear dependency can be expressed as follows: 
(11) $\left.\sum_{\substack{r=A^{*} \\ r \neq j}}^{A^{* *}}(j-r)\left[A_{r}\right]+\sum_{\substack{s=Y * \\ s \neq k}}^{Y * *}(s-k)[Y]=c_{t * k}^{C *}\right](t-m)\left[C_{t}\right]$

Therefore, we can write

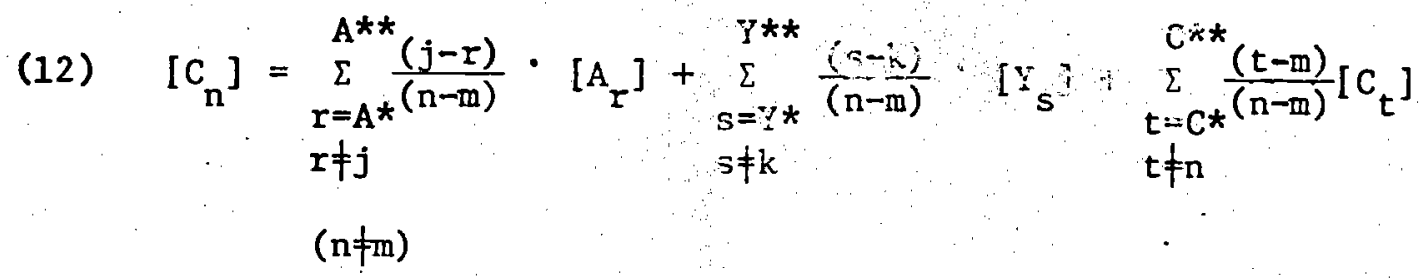

Substituting the value of $\left[\mathrm{C}_{n}\right]$ in Equalion 12 into Equation 10 , we obtain

$$
\begin{aligned}
& {\left[\operatorname{lnp}_{\ell}\right]=\sum_{\substack{r=A * \\
r \neq j}}^{A * *}\left\{\alpha_{r \ell}-\alpha_{j \ell}+\left(\frac{j-r}{r-m}\right) \quad\left(\alpha_{j l} \cdot \beta_{k \ell}+y_{n \ell}\right)\right\}\left[A_{r}\right]}
\end{aligned}
$$

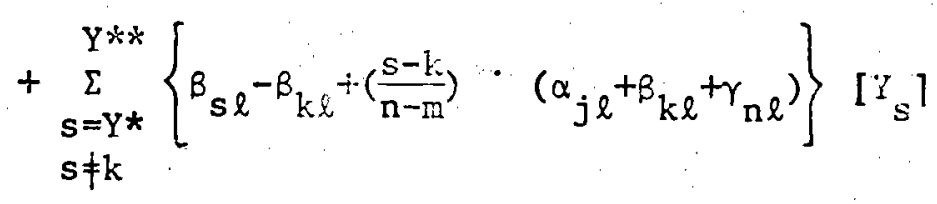

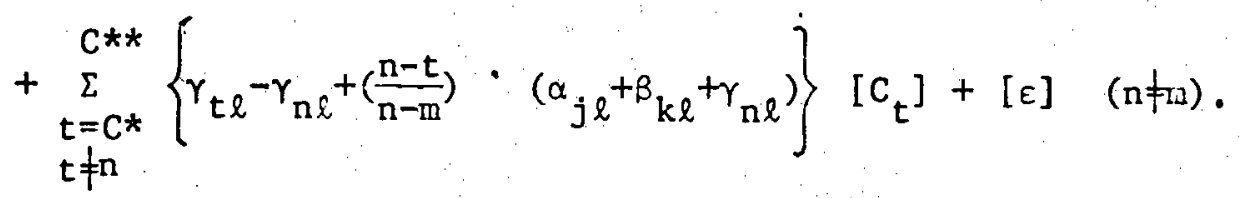

Equation 13 is estimable, and we can illentify the $\left(\alpha_{\mathrm{r} \ell}{ }^{-\alpha_{j \ell}}\right),\left(\beta_{s \ell}{ }^{-\beta_{k \ell}}\right)$, and the $\left(\gamma_{t \ell}-\gamma_{n \ell}\right)$ if we knew $\left(\alpha_{j \ell}+\beta_{k \ell}+\gamma_{n \ell}\right)$. Let us denote this latter sum by $x_{\ell}$ Clearly we cannot use the goodness of fit to help us determine $x_{\ell}$, since the regression coefficients are not affected by its value and further there is no observed birth probability for the combination of age $j$, current year $k$, 
we must use some additional information to compute the $x_{\ell}$.

We have estimated Equation 13 for the first four birth orders. For birth orders one through three, we used ages 18 through 39 , omitting age 30 , current years 1920 through 1966 omitting 1960 and the war-affected years of 1942 through 1947, and cohorts 1900 through 1946, omitting women born in 1931. In terms of the notation of Equation 13, $j=30, k=1960$, $m=1930$, and $n=1931$. For birth order four we followed the pattern of the first three birth orders except that ages 22 through 39 , current years 1924 through 1966, and cohorts 1900 through 1942 were used. This procedure yielded three regressions with 107 dummy variables and 705 observations each and one regression with 95 dummy variables and 595 observations. The results of these computations are reported in Appendix III. Before the results of these regressions can be used we must compute the $x_{\ell}$. We know that the decline in birth probabilities from 1930 to 1933 ought not to be attributed to a fortuitous configuration of age and cohort components, but rather to a decline in the currert year component. Similarly the increase in birth probabilities from 1933 to 1934 ought to be accounted for mainly be an increase in the current year component. Let us denote the coefficient of $\left[Y_{s}\right]$ in Equation 13 by $D_{8 \ell} \cdot$ Then we can write:

(14) $B_{1933, \ell}-B_{1930, \ell}=D_{1933, \ell}-D_{1930, \ell}+3 \cdot X_{\ell}$ and

(15) $\quad B_{1933, \ell}-B_{1934, \ell}=D_{1933, \ell}-D_{1934, \ell}-X_{\ell}$. 
If estimates could be made of $\beta_{1933, \ell}-\beta_{1930, l}, \beta_{1933, l}-\beta_{1934, l}$, or Indeed any current year component difference, then the value of $x_{\ell}$ could be estimated. Any estimate of current year components drawn from observed data must be confounded with age and cohort Influences. There is no way around this problem. The tack taken here is to try to minimize the effects of age and cohort influences by choosing to estimate current year component differences using observed data for years for which there is a priori information that changes in current year conditions were of speical importance in explaining fertility variations.

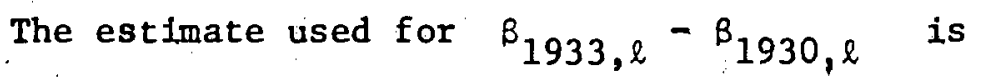

$$
d_{1, \ell} \equiv \frac{\sum_{i=15}^{30} \ln \left(p_{i, 1} 1933, k, \ell\right)-\ln \left(p_{i, 1930, k-3, \ell}\right)}{16}
$$

where. $k=1933-1$. The estimate used for $\beta_{1933, l}-\beta_{1934, l}$ is

$$
\mathrm{d}_{2, \ell} \equiv \sum_{i=15}^{33} \ln \left(\mathrm{p}_{1,1933, k, \ell}\right)-\ln \left(\mathrm{p}_{i, 1934, k+1, \ell}\right)
$$

where $k=1933-i$ once more, The criterion we used to determine $\mathrm{x}_{2}$ was: 


$$
\text { Mintmize }\left\{\frac{l}{3}\left(D_{1933, \ell}-D_{1930, \ell}+3 x_{\ell}-d_{1, \ell}\right)\right\}^{2}+\left\{D_{1933, \ell}-D_{1934, \ell}-x_{\ell}-d_{2, \ell}\right\}^{2}
$$

In essence, this criterion allows the selection of that $x_{\ell}$ whose implications for current year components fit most closely the notions that the declines in birth probabilities from 1930 to 1933 and the subsequent increases to 1934 were mainly due to changes in current year components.

Given the values of $x_{\ell}$ computed from the criterion above, we have computed the current year component differences $\left(\beta_{s, l^{-}} \beta_{1960, \ell}\right)$ and the cohort component differences $\left(\gamma_{t, l}-\gamma_{1931, \ell}\right)$. The current year component differences are shown in Graphs 4,6, 8, and 10, and cohort component differences in Graphs 5, 7,9, and 11. The data shown in these graphs are sensitive to the criterion chosen to estimate the $x_{\ell}$ and by no means ought the plotted data to be interpreted as being precise. However, the general patterns shown by the component differences remain given any plausible criterion of which we are aware.

Graph 4 shows the current year component differences for first b1rths. It is somewhat surprising to note that the current year component for first births does not peak in 1957, but earlier in the baby boom decade. How then are we to understand the first birth probabilities of women 15 through 27, all of which peak in 1957? The answer can be found 
by turning to Graph 5. Here we can see that the cohort component was rising after the middle of the $1920^{\prime} \mathrm{s}$. It is the rise, particularly the increase for women born in the Depression which is the main cause of the increase in first birth probabilities for young women during the baby boom. The rather large differences in the behavior of first birth probabilities by age group which we noted earlier in the paper can be traced directly to variations in the cohort components.

Clearly, if we are to understand the increase in first births over the course of the baby boom, we must focus our attention on the large upward movement of the cohort component which occurred across the Depression. Apparently relative cohort size has some impact on this component because the small cohort of 1919 has a relatively large component and the relatively large cohort of 1921 a comparatively small one. The year 1917 for which the cohort component has a local trough is also a year in which the birth series has a local peak. ${ }^{19}$ Nonetheless, the sheer size of the change in the cohort component over the Depression relative to previous changes suggests that some other factors were also at work. Perhaps one of the other factors is the Easterlin-Fuchs intergenerational relative income effect. However, it is not evident that these two factors taken together would imply a 1941 peak in the cohort component. In any case, one thing is clear from Graph 5, cohort components have been the source of a considerable portion of the variability in first birth probabilities over the baby boom. 


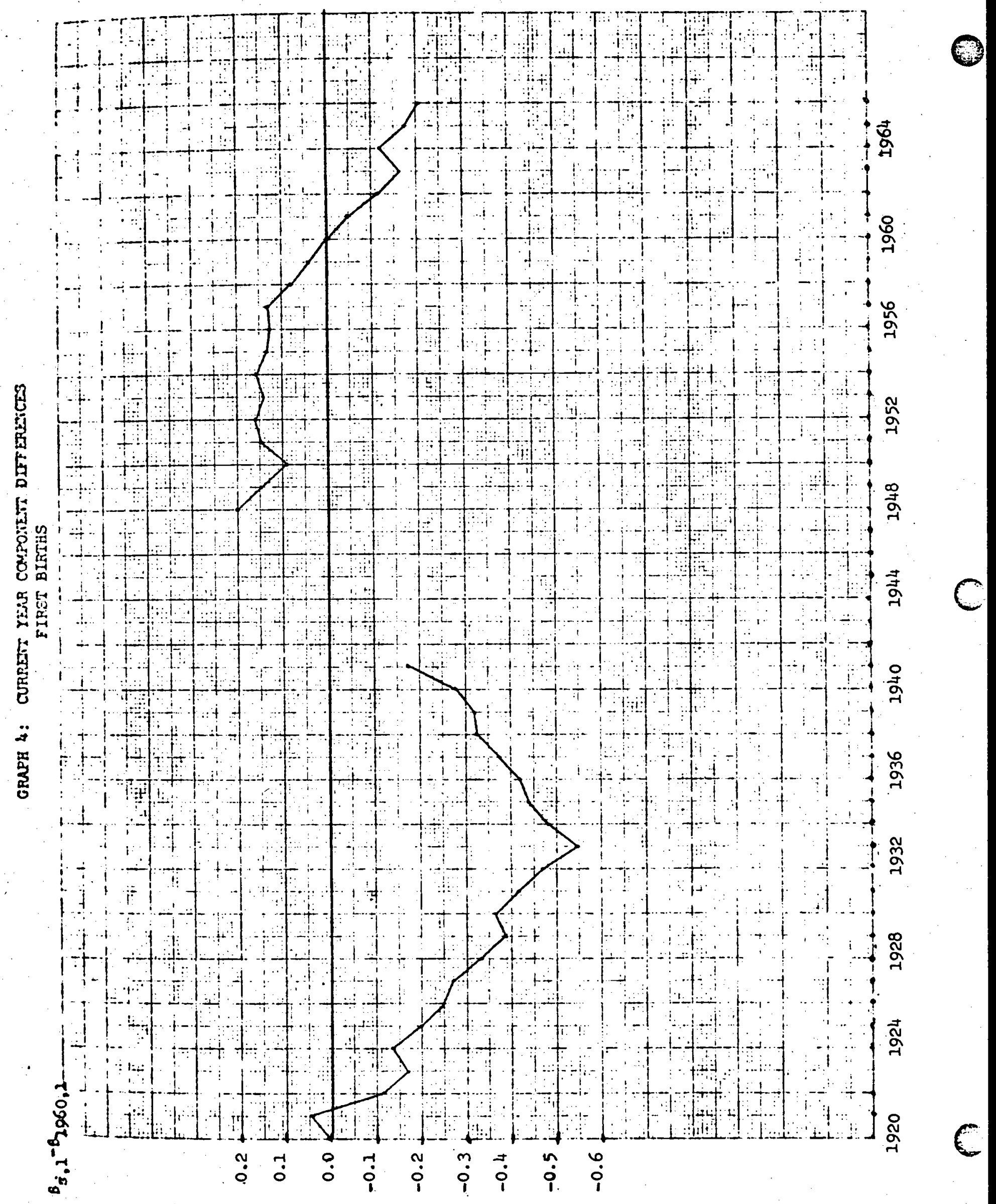


3

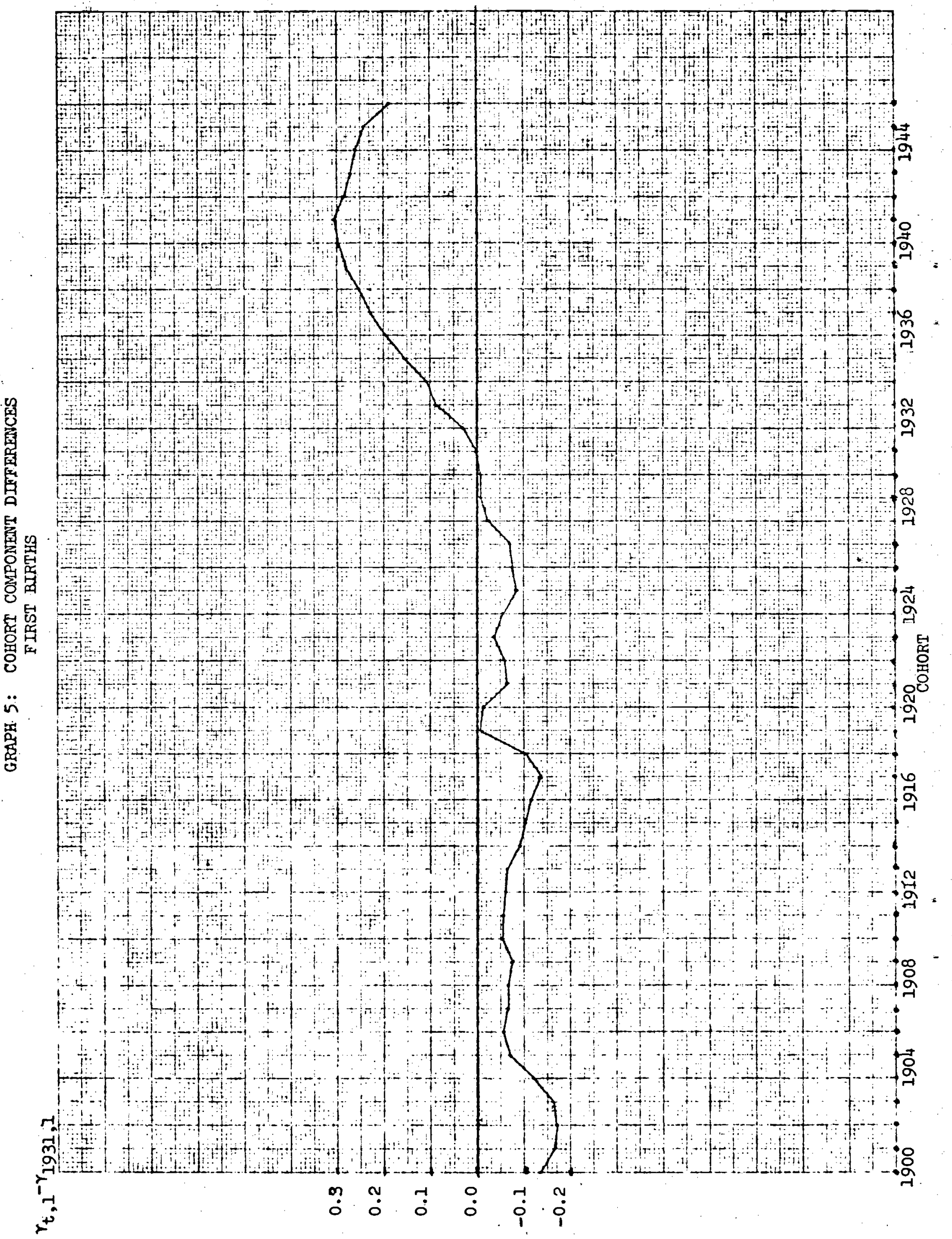




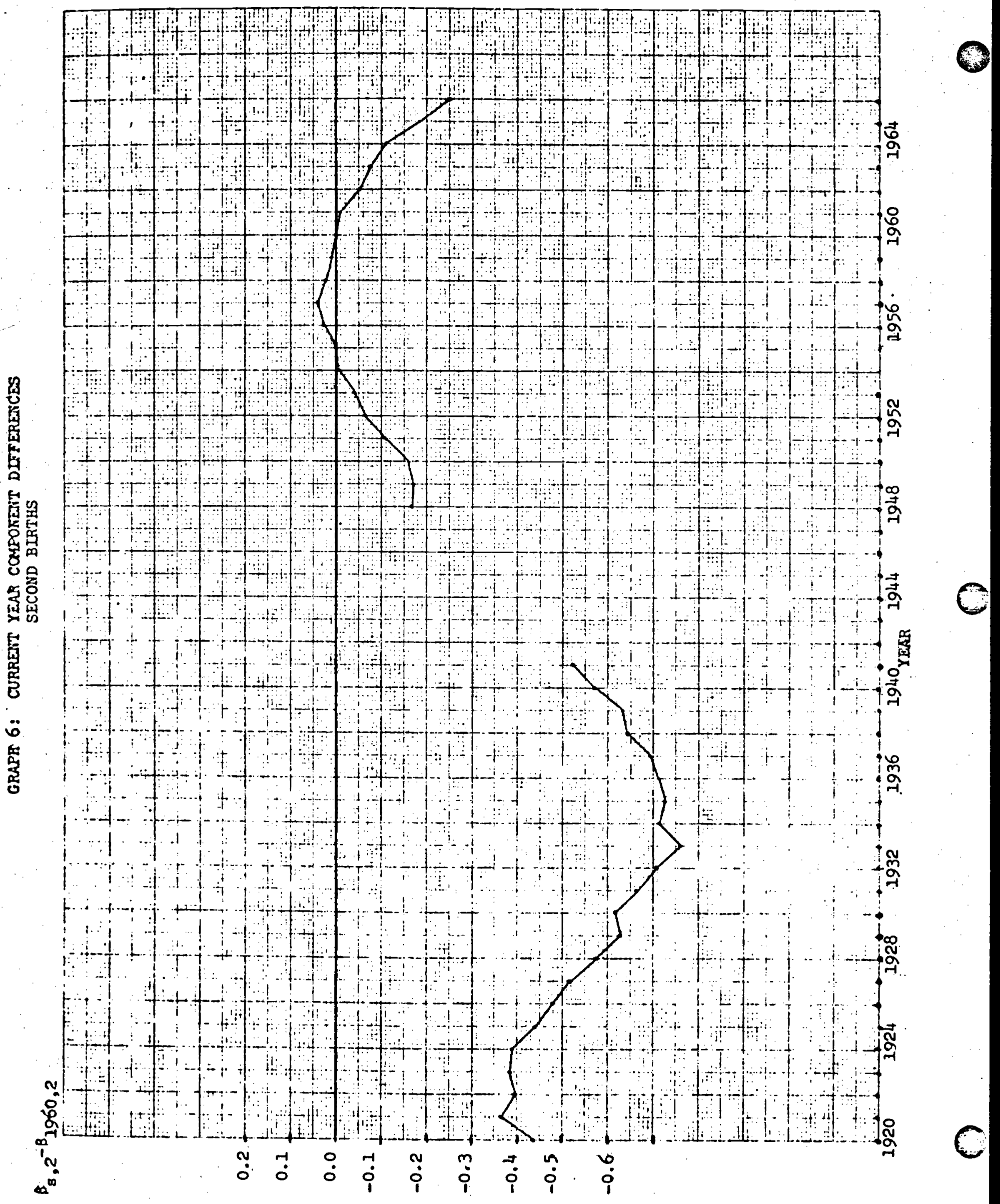


3
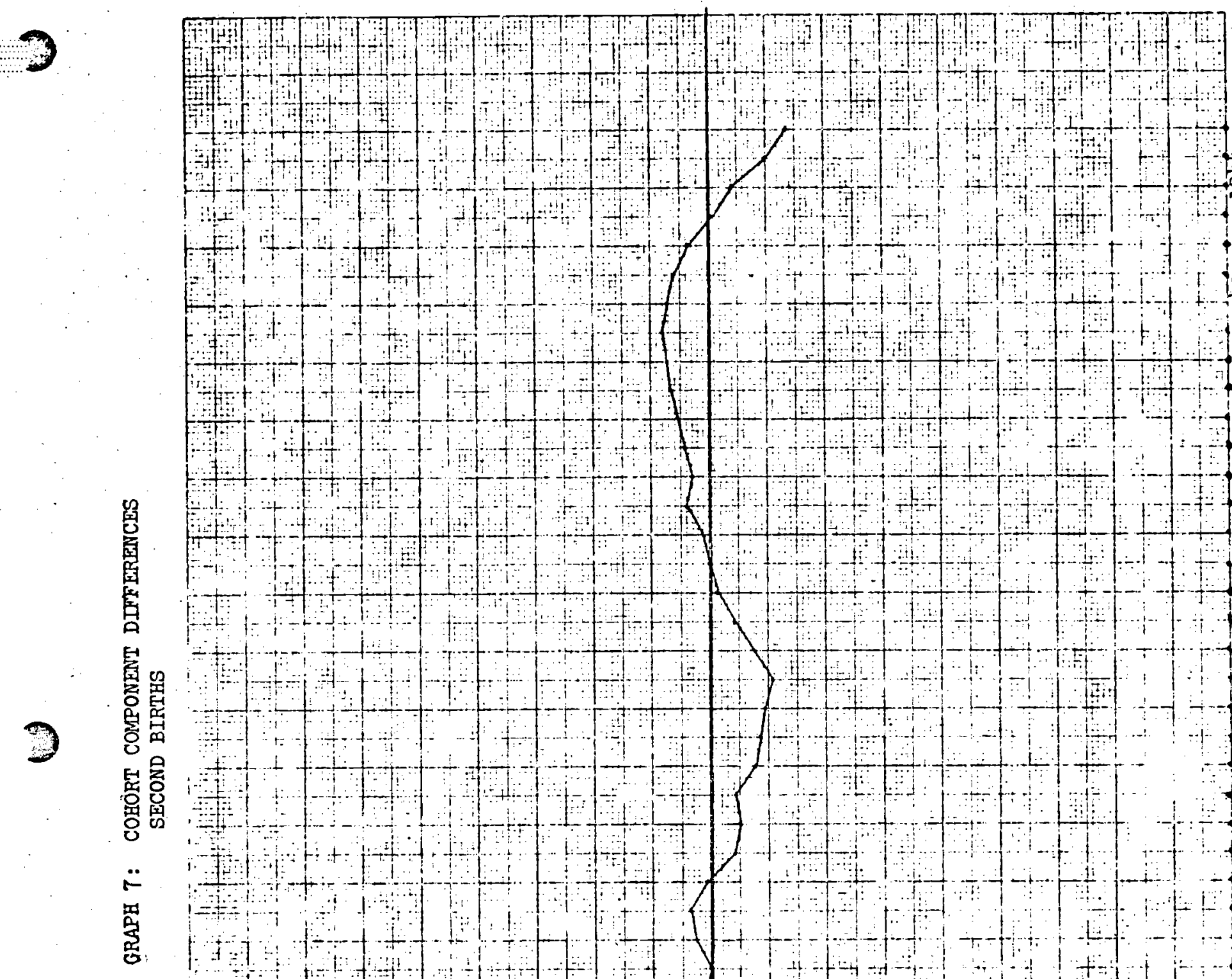

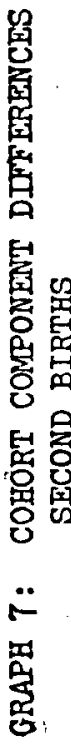

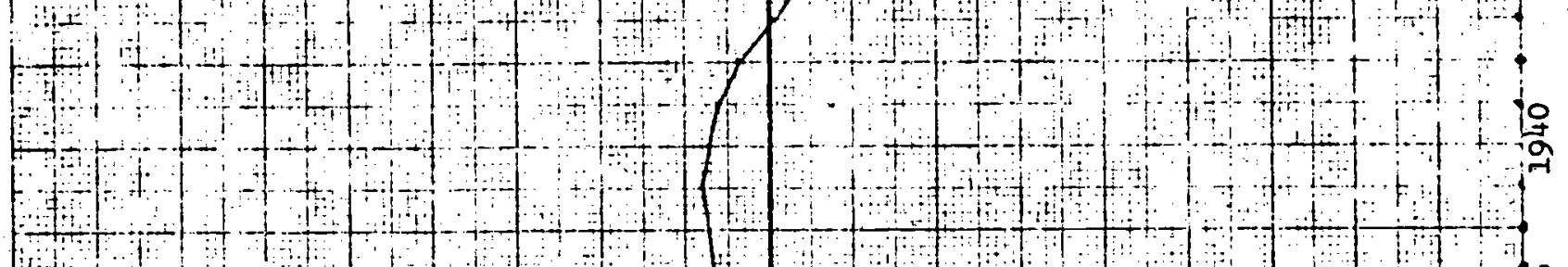

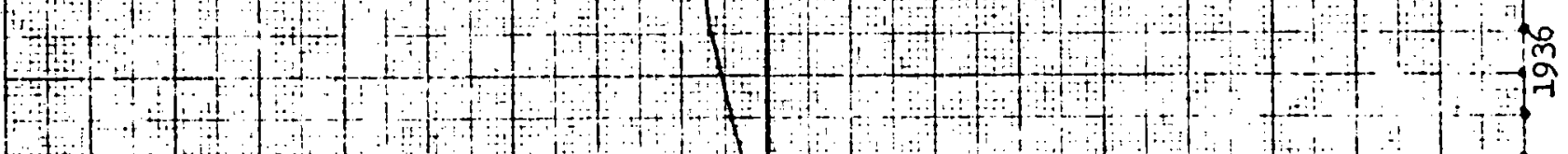
$+4+1+1+1$

$1+2+10$

$7+1+C+C$

标

$10+1+1+1$

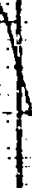

$1+1+1+4$

1

1

$+\frac{1}{10}+\frac{1}{2}$

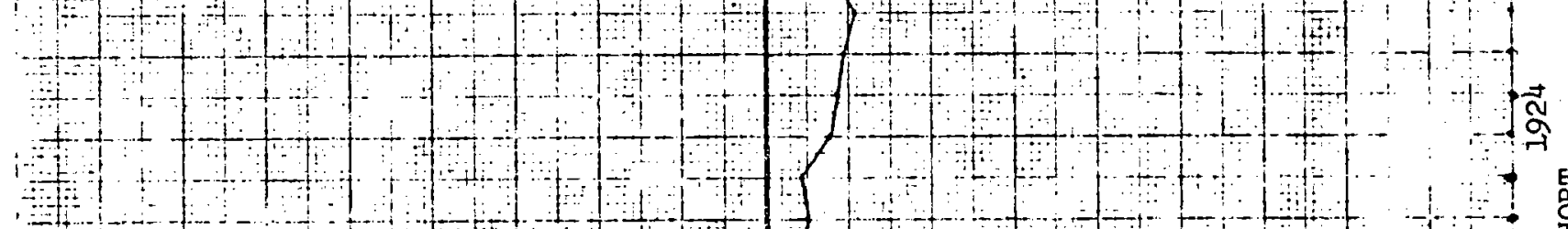

每

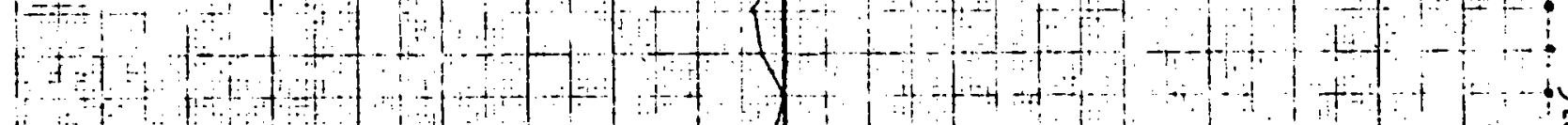

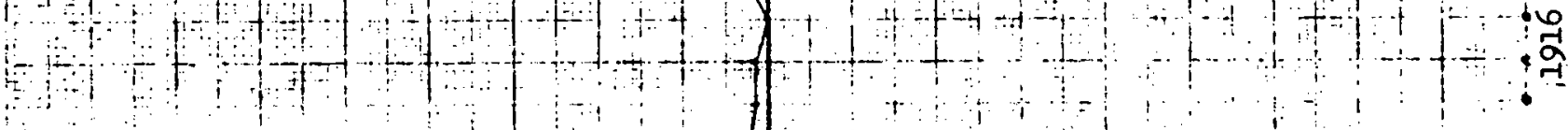

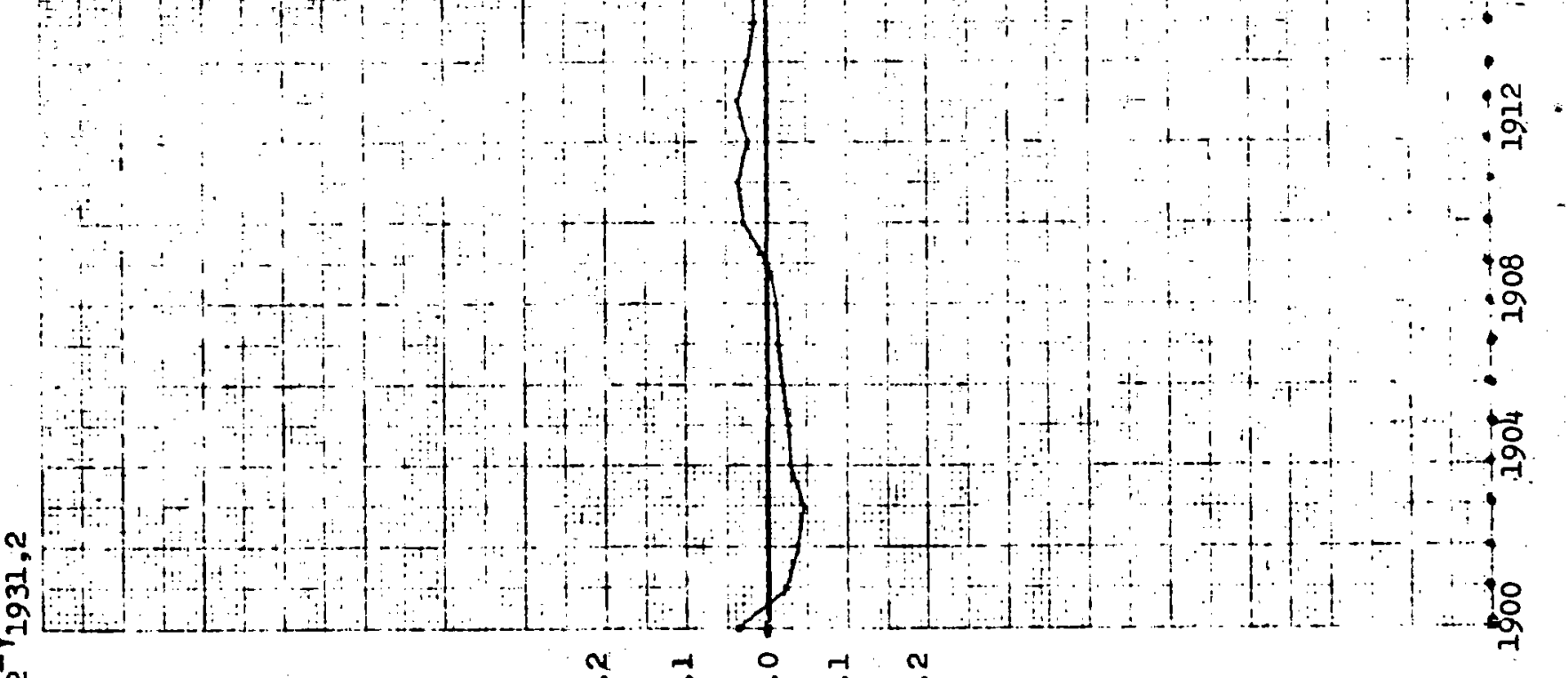

3

s

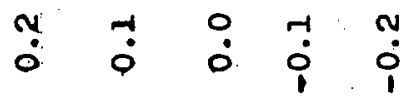




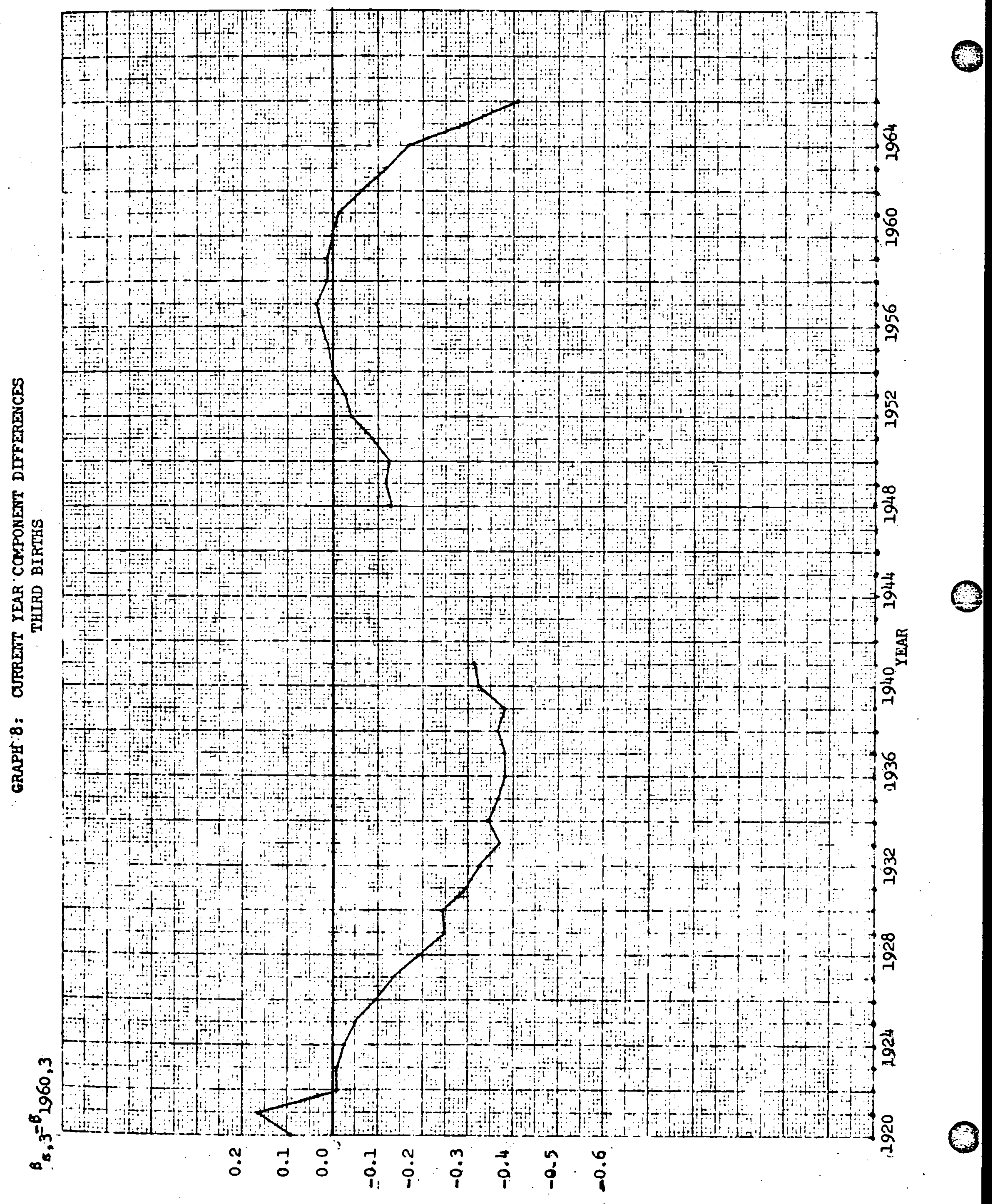




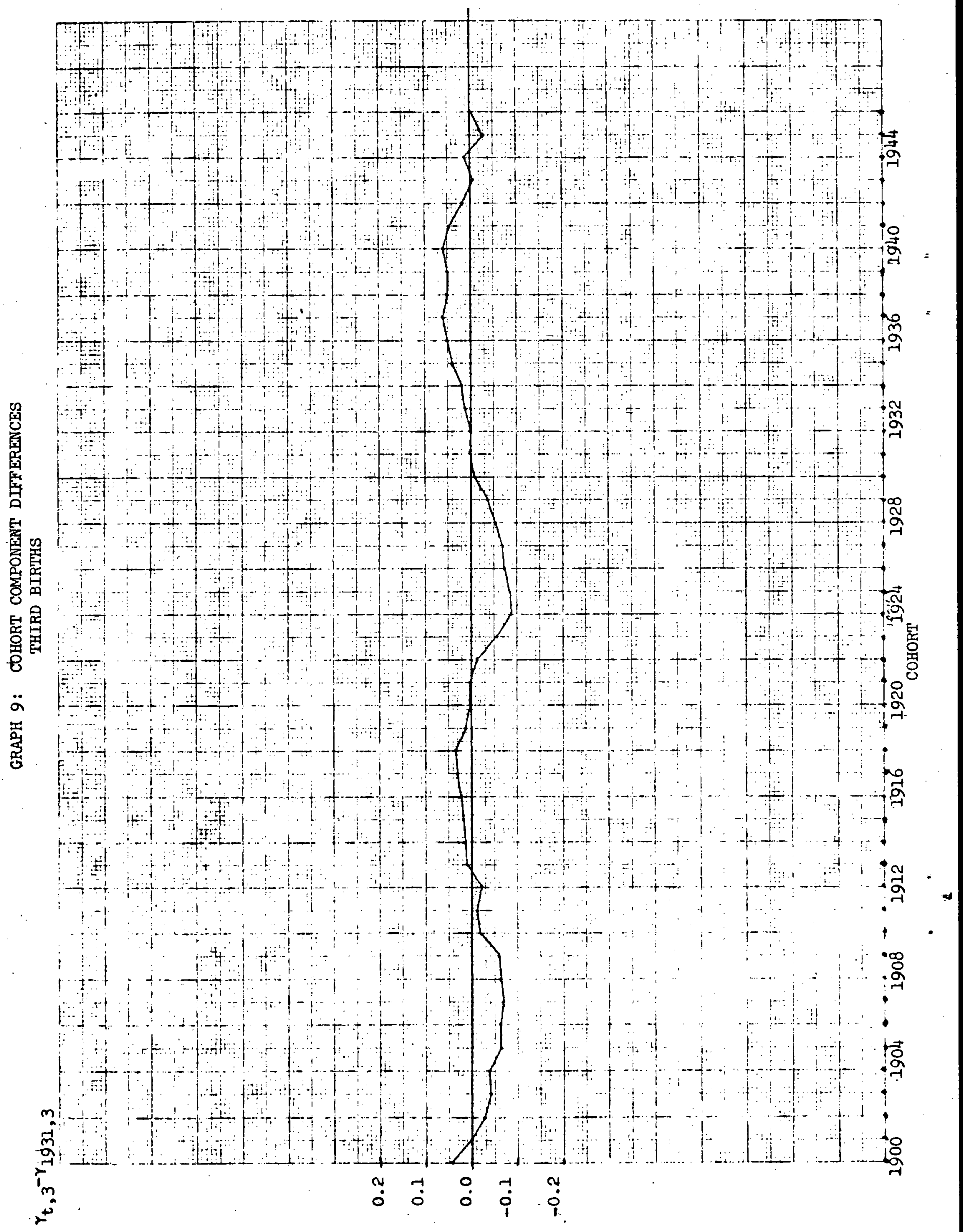




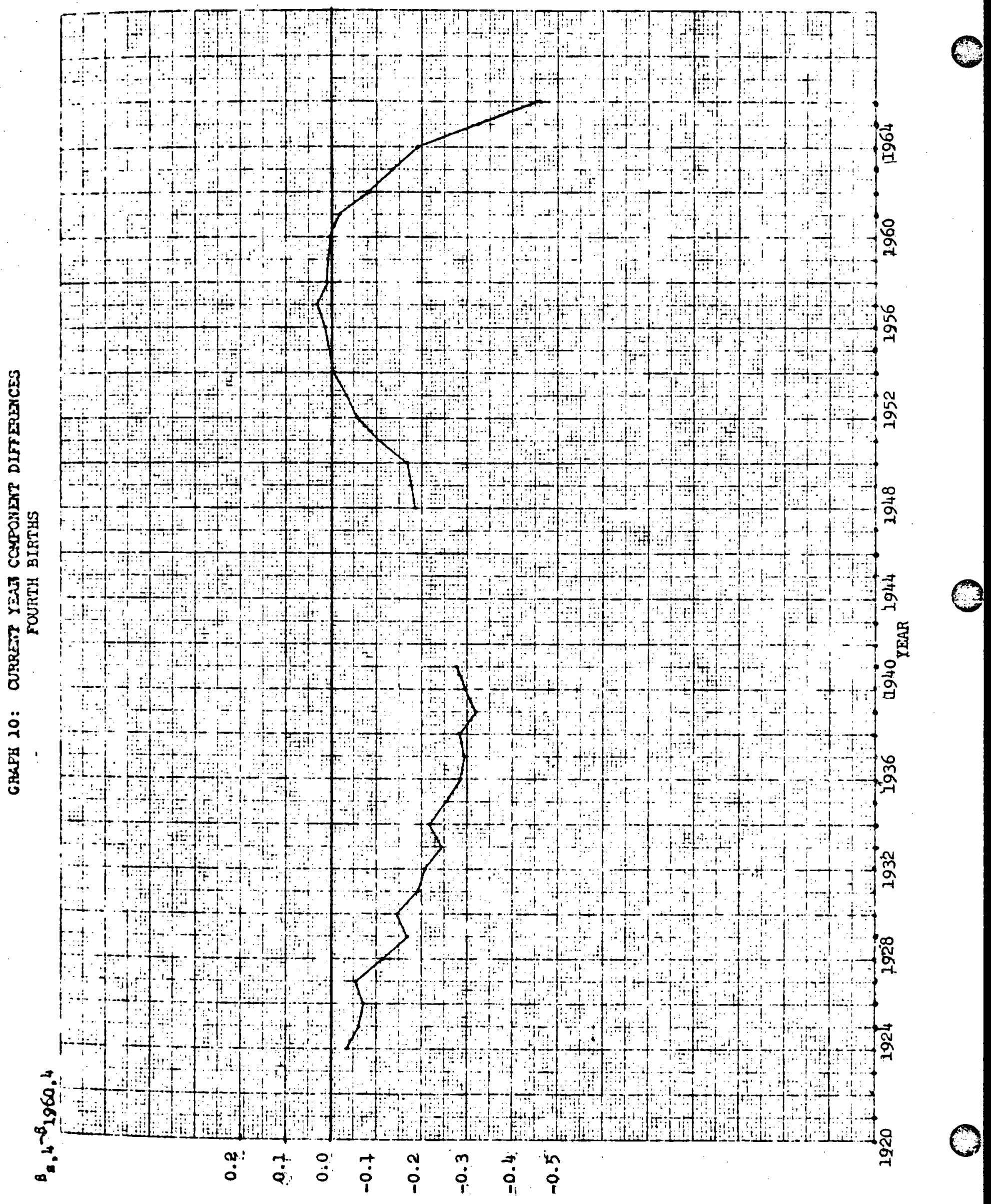




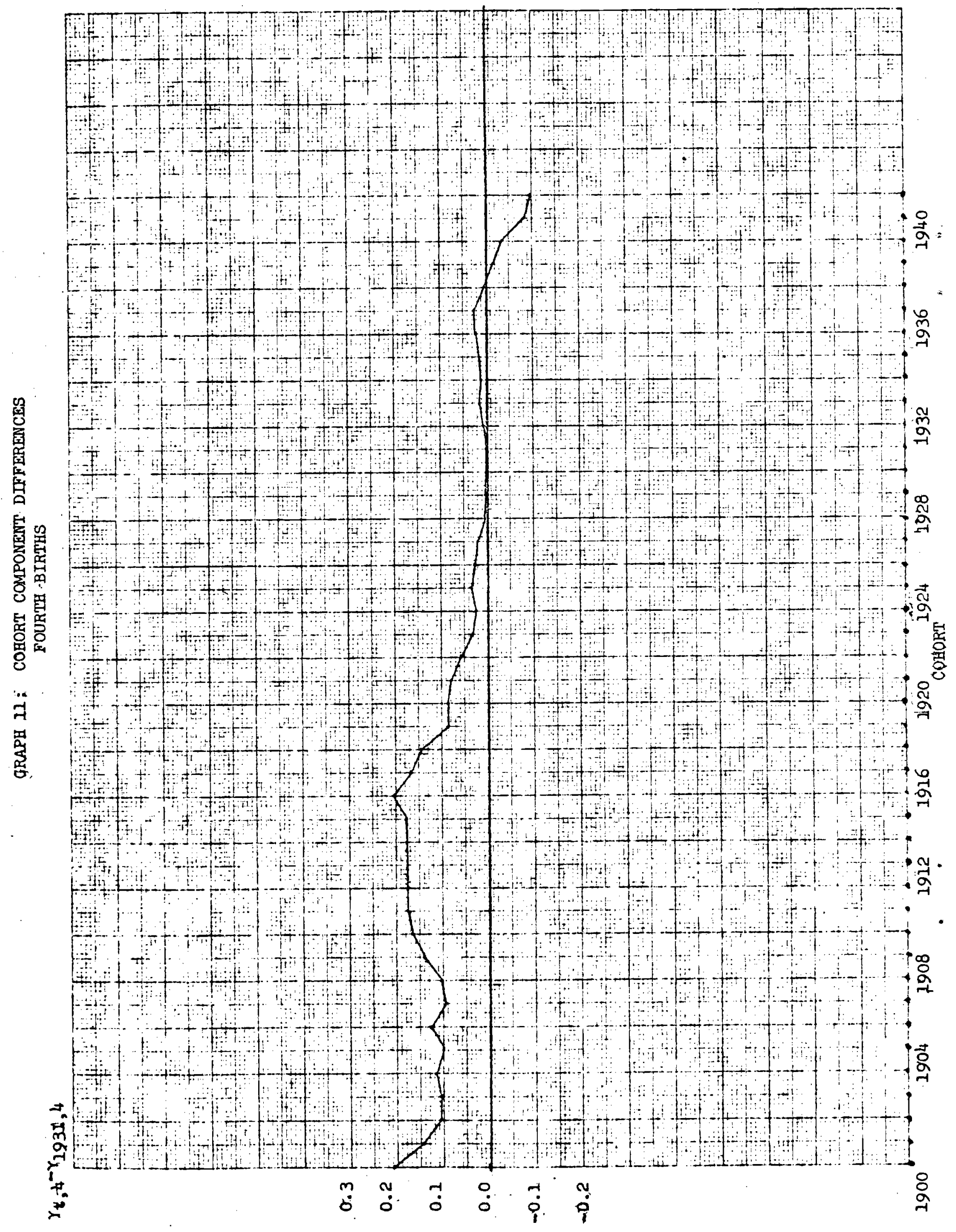


Looking at Graphs 6,8 , and 10 , one can see a common pattern in the current year components; one that is different from that in Graph 4. In Graph 4, we found that the current year component for first births did not rise in the 'fifties to a peak in 1957.' In Graphs 6, 8, and 10 , we see that the current year components for second through fourth births do rise in the 'fifties to a peak in 1957. It is in part this this difference between the behavior of the current year component for first and for higher order births. which explains why birth probability patterns differ by order for women of the same age, the phenomenon we observed in Graph 3 above. This clear differentiation between the current year components of first births and higher order births during the baby boom period is an important observation. It suggests that students of fertility might profitably study first and subsequent births separately. Considering the cohort componmats of second through fourth births, it can be seen that the rise in the cohort component over the Depression which was so prominent with respect to first births becomes significantly attenuated as birth order increases. In Graph 11, which shows the cohort components for fourth births, the rise over the Depression is so small as to be almost nonexistent. Thus it appears that at least some cohort influences affect fertility by primary affecting low order births.

We are now in a position to systematize the observations we made on the patterns of birth probability changes over the baby boom. Most of the age differentiation in the patterns of birth probabilities may be explained by 
a comon pattern in the cohort components. Cohort components tended to have a declining phase in the 'twenties followed by an increasing phase beginning in the middle or late 'twenties. This pattern raised the fertility of younger women in the 'fifties and lowered the fertility of older women. The increasing phase of the cohort component clearly grew smaller in amplitude as birth order increased and it is possible that the reverse happened with respect to the decreasing phase. Most order differentiation in the patterns of birth probabilities by age occurs between first and subsequent births due to the change in the pattern of current year components from one which is relatively flat from 1952 through 1957 and which falls thereafter to a pattern for second and higher order births which is more rounded and which peaks in 1957. The less rapid fall from 1957 to 1960 in this latter pattern accounts for why the interaction between it and the cohort components produces peaks around 1960 rather than the earlier peaks in the first birth probabilities of young women.

In this paper we have presented data on monthly birth probabilities for native white women which are age- and parity-specific, We have considered the patterns of variation shown by these probabilities over the baby boom and demonstrated that these patterns may be illuminated by decomposing the birth probabilities into age, current year, and cohort components. It is hoped that the data presented here and the questions which hve been raised will aid in the development of models and data which will deepen our understanding of the intricate processes of fertility change over time. 
APPENDIX I

The Methodology of the Creation of Birth Probabilities.

As an example, we shall relate in detail the creation of the monthly probability of 30 year old women having thelr second birth in 1950 . Plrst, we assume that women are only born on the first day of every Donth. This assumption makes our computations managable without neglecting the substantial variations in monthly births which have occurred. Women who report having a second birth at age 30 in 1950 may have been born between February 1, 1919 and December 1, 1920. In other words, the women may have any one of twenty-three monthly birthdays. Let us call women born on February 1, 1919 members of cohort one, women born on March 1, 1919 members of cohort two, and so on. Women born on December 1, 1920 are members of cohort 23. In order to determine the birth probability we must know how many women are capable of having a second birth at age 30 in 1950 and how many months these women spend as 30 year olds in 1950. We have assumed in the birth probability computations that a woman was not capable of having a birth untll twelve months after her last one except in the case of twins.

The assumption that, except in the case of twins, a woman was not capable of having a birth in less than twelve months after her last one, forces us to divide those women capable of having a second birth at age 30 in 1950 into two groups, those who have had their first b1rth more than a year before they turn 30 in 1950 and those who have had thelr first birth within a year of the date on which they turn 30 in 
1950. Let us consider, for example, those women of cohort 12

(i.e. those born on January 1, 1920) who are capable of having a second birth at age 30 in 1950. Some of these women had their first birth when they were 20 in 1949. If their births were distributed uniformly over the year 1949, these women would have, on average, six months of 1950 in which they were capable of having a second child. Wumen who had their first birth before they were 29 in 1949 would have a full twelve months of 1950 in which they were capable of having a second child.

$$
\text { Let us define } \mathrm{N}_{1,1} \text { through } \mathrm{N}_{23,1} \text { as the numbers of }
$$
women in cohorts 1 through 23 who have had their first child before age 29 in 1949 and $\vec{N}_{1,2}$ through $\mathrm{N}_{23,2}$ as the numbers of women in cohort 1 through 23 who had their first birth at age 29 in 1949 . If these numbers of women are known and the total number of second births to 30 year old women in 1950 , called $B$, is known, we can write the following equation in which $p$ is the monthly probability of having a second birth. 
(1) $B=\sum_{j=1}^{2} \sum_{i=1}^{23} N_{1 j}-\sum_{j=1}^{2} \sum_{i=1}^{12} N_{1 j}(1-p)^{1 / j}-\sum_{j=1}^{2} \sum_{i=13}^{23} N_{1 j}(1-p)(24-1) / j$

Equation 1 is not easily solved for $p$ in general. However since we know that $p$ is generally quite small, of ten around 0.02 , a Taylor series expansion of the terms involving $(1-p)$ in which we delete all terms above the quadratic one will yield a good approximation.

In general, we can write

(2)

$$
(1-p)^{n} *(1-q)^{n}+n(1-q)^{n-1}(q-p)+\frac{(n)(n-1)(1-q)^{n-2}(q-p)^{2}}{2}
$$

Ho can rewrite equation 2 as follows

$$
(1-p)^{n}=(1-q)^{n}+n(1-q)^{n-1} q+\frac{(n)(n-1)(1-q)^{n-2} q^{2}}{2}
$$

(3)

$$
\begin{aligned}
& -p\left[n(1-q)^{n-1}+(q)(n)(n-1)(1-q)^{n-2}\right] \\
& +p^{2}\left[\frac{(n)(n-1)(1-q)^{n-2}}{2}\right]
\end{aligned}
$$

let us make the following definftions:

$$
\begin{aligned}
& P(q, n)=(1-q)^{n}+(n)(1-q)^{n-1} q+\frac{(n)(n-1)(1-q)^{n-2}(q)^{2}}{2} \\
& c(q, n)=n(1-q)^{n-1}+(q)(n)(n-1)(1-q)^{n-2} \text { and } \\
& u(q, n)=\frac{(n)(n-1)(1-q)^{n-2}}{2}
\end{aligned}
$$


Equation 1 may now be written

$$
B-\sum_{j=1}^{2} \sum_{i=1}^{23} N_{i j}-\sum_{j=1}^{2} \sum_{i=1}^{12} N_{i j}\left[F(q, i / j)-p G(q, i / j)+p^{2} H(q, i / j)\right]
$$

(5)

$$
\sum_{j=1}^{2} \sum_{1=13}^{23} N_{1 j}\left[F\left(q, \frac{24-i}{j}\right)-p G\left(q, \frac{24-i}{j}\right)+p^{2} H\left(q, \frac{24-i}{j}\right)\right] .
$$

Writing equation 5 in the standard form of a quadratic equation we obtain

$$
\begin{aligned}
& p^{2}\left[\sum_{j=1}^{2} \sum_{i=1}^{12} N_{i j} H(q, i / j)+\sum_{j=1}^{2} \sum_{i=13}^{23} N_{i j} H\left(q, \frac{24-i}{j}\right)\right] \\
& +p\left[-\sum_{j=1}^{2} \sum_{i=1}^{12} N_{i j} G(q, i / j)-\sum_{j=1}^{2} \sum_{i=13}^{23} N_{i j} G\left(q, \frac{24-1}{j}\right)\right] \\
& +\sum_{j=1}^{2} \sum_{i=1}^{23} N_{i j}-\sum_{j=1}^{2} \sum_{i=1}^{12} N_{i j} F(q, i / j)-\sum_{j=1}^{2} \sum_{i=13}^{23} N_{i j} F\left(q, \frac{2 L-i}{j}\right)-B=0 .
\end{aligned}
$$

Equation 6 can be easily solved for $p$ and its solution clearly depends on the Initial value of $q$ which is chosen. In the computation of the birth probabilities $q$ was initially set at 0.05 . After $P$ was computed by solving equation 6 , the new $p$ was introduced as the value of $q$ and $p$ was computed once again. Through experimentation it was found that the value of $p$ almost always converged to its true value after two iterations. 
The underlying birth data for the years 1915 through 1946 are implicit in Whelpton (1954), and data for the years 1947 through 1966 are derived from the relevant issues of Vital Statistics of the United States. The data on the number of women capable of having a birth of a given order at a given age in a given year and essentially derived, simultaneously with the birth probabilities. For example, we assume that women do not give birth to children before the age of 15 . Therefore, once we have computed first birth probabilities for 15 year old women, we can determine the number of months of exposure to having a second birth 16 year old women have in the subsequent year. For more details on this procedure see Sanderson (1974) Appendix A. 

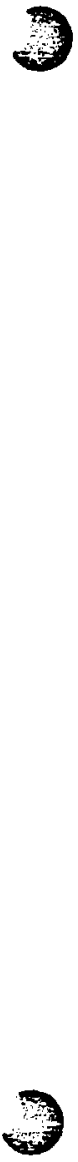

APPENDIX II

$\leftarrow$

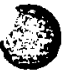




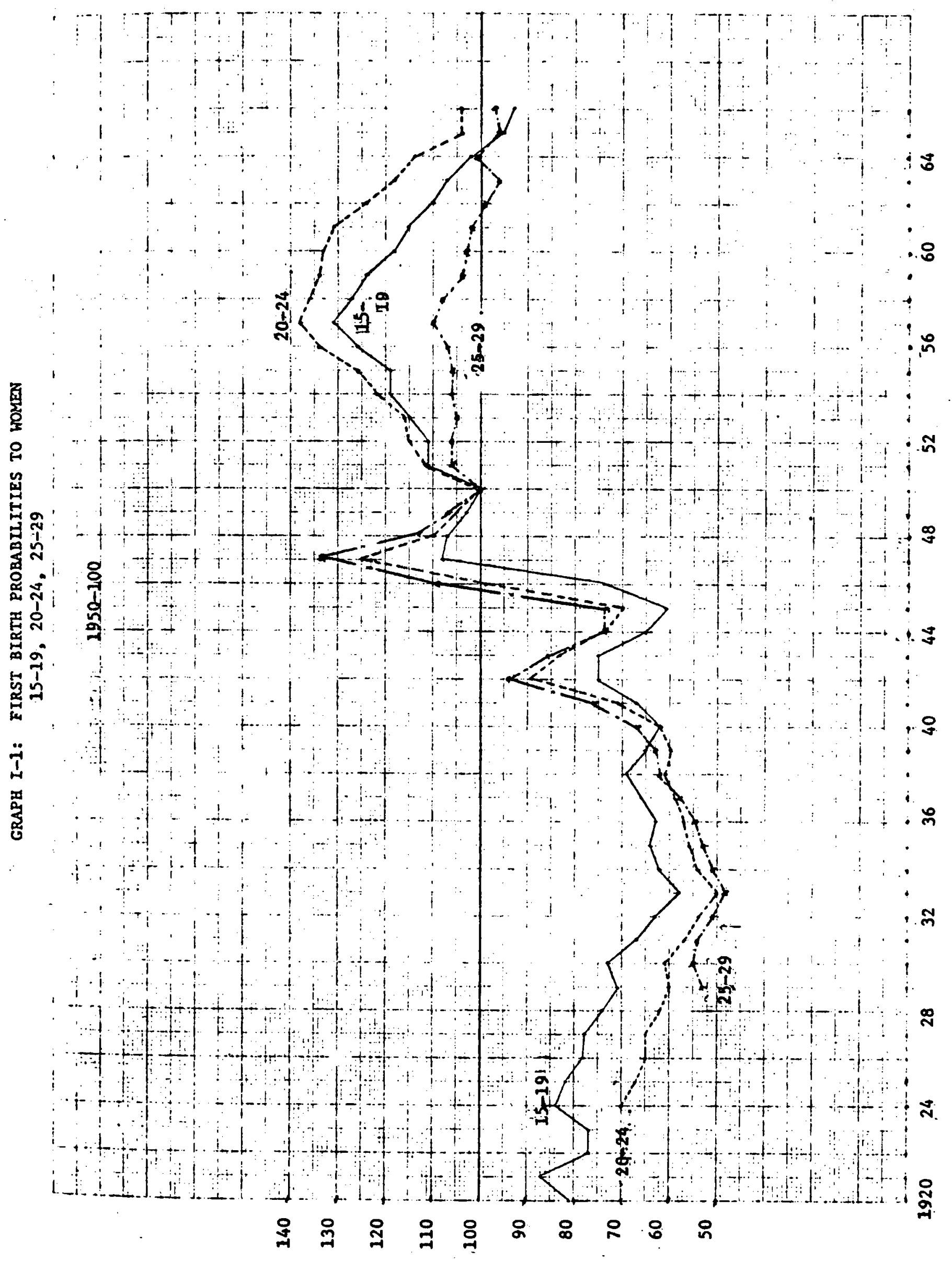


mat

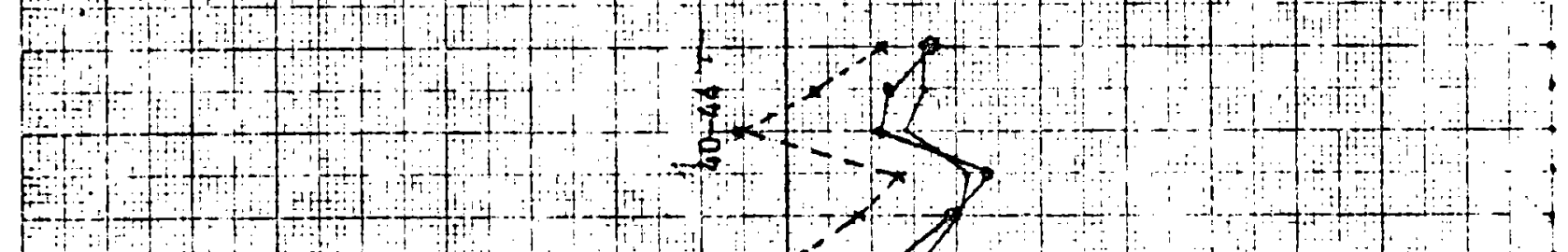

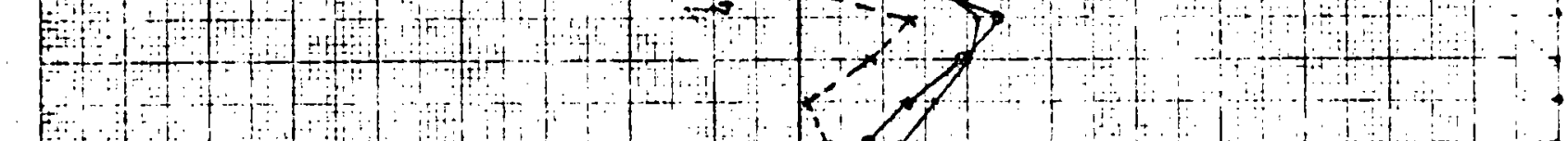

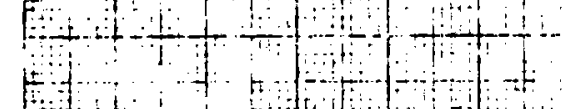

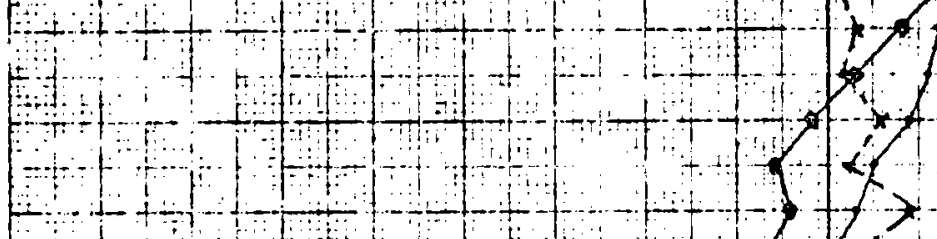

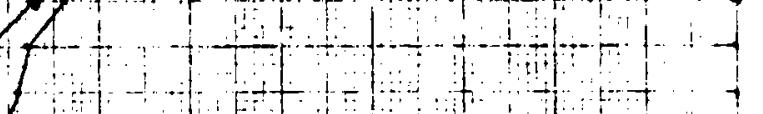

Di 


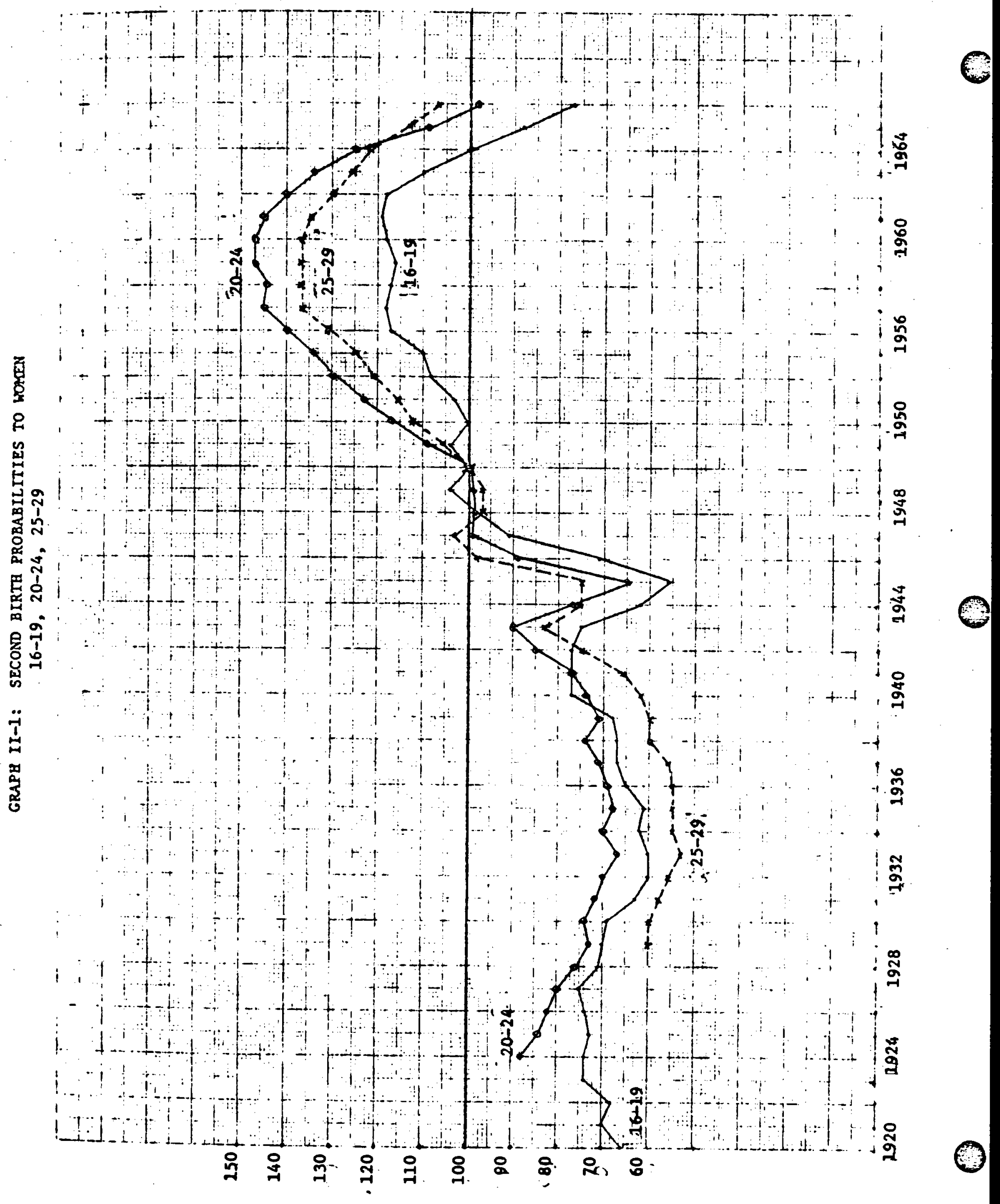


3

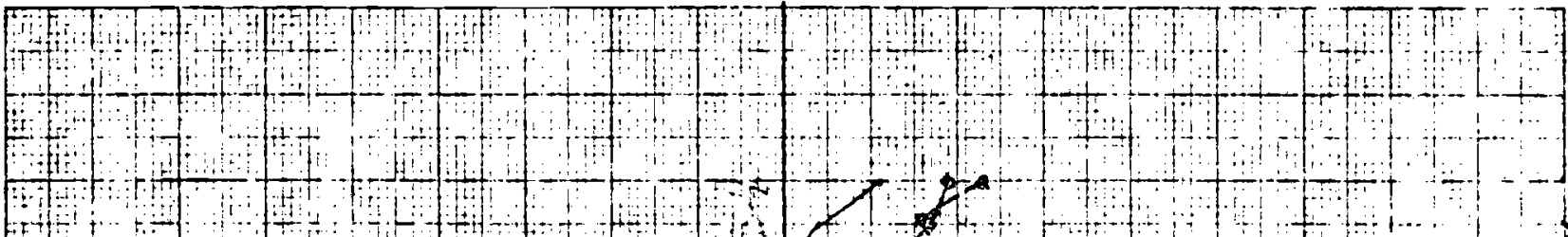

$5+10+0$

$+1+1$ d d

Pation

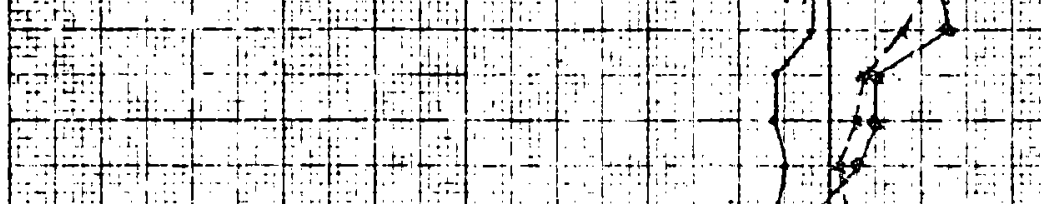

$7+1+4 \mathrm{Cl}^{2}$

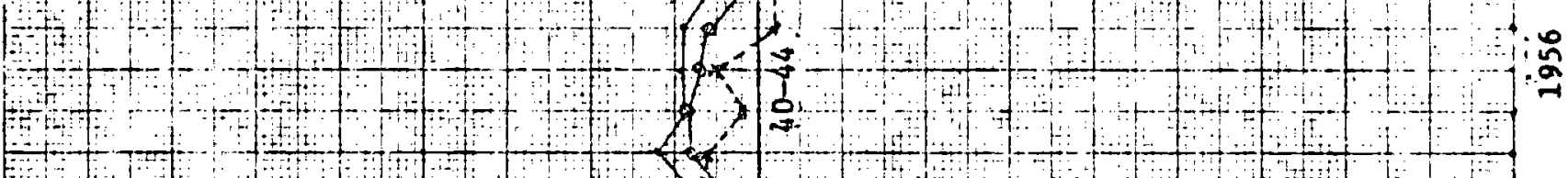

-

$1+1+1+C$

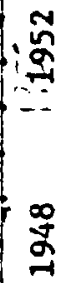

$\frac{8}{8}$

.

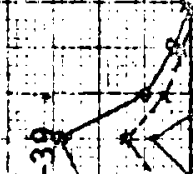

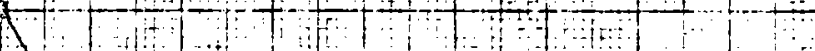

a d a d a

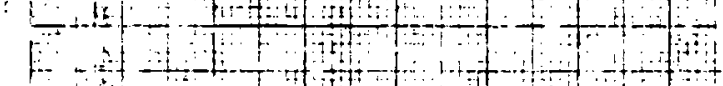

ind

$+$

$1 T+1+1+1$
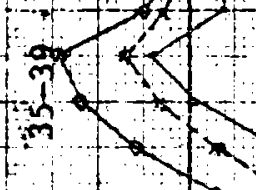

$3 \times 1+1$

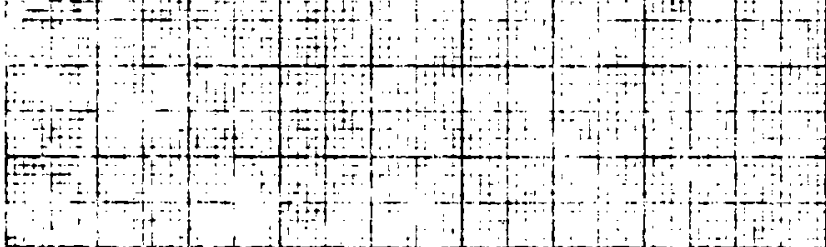

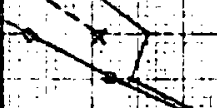

$+4+4$

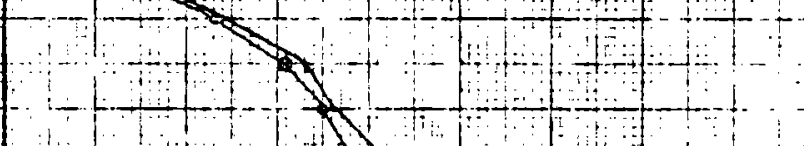

过

fo 


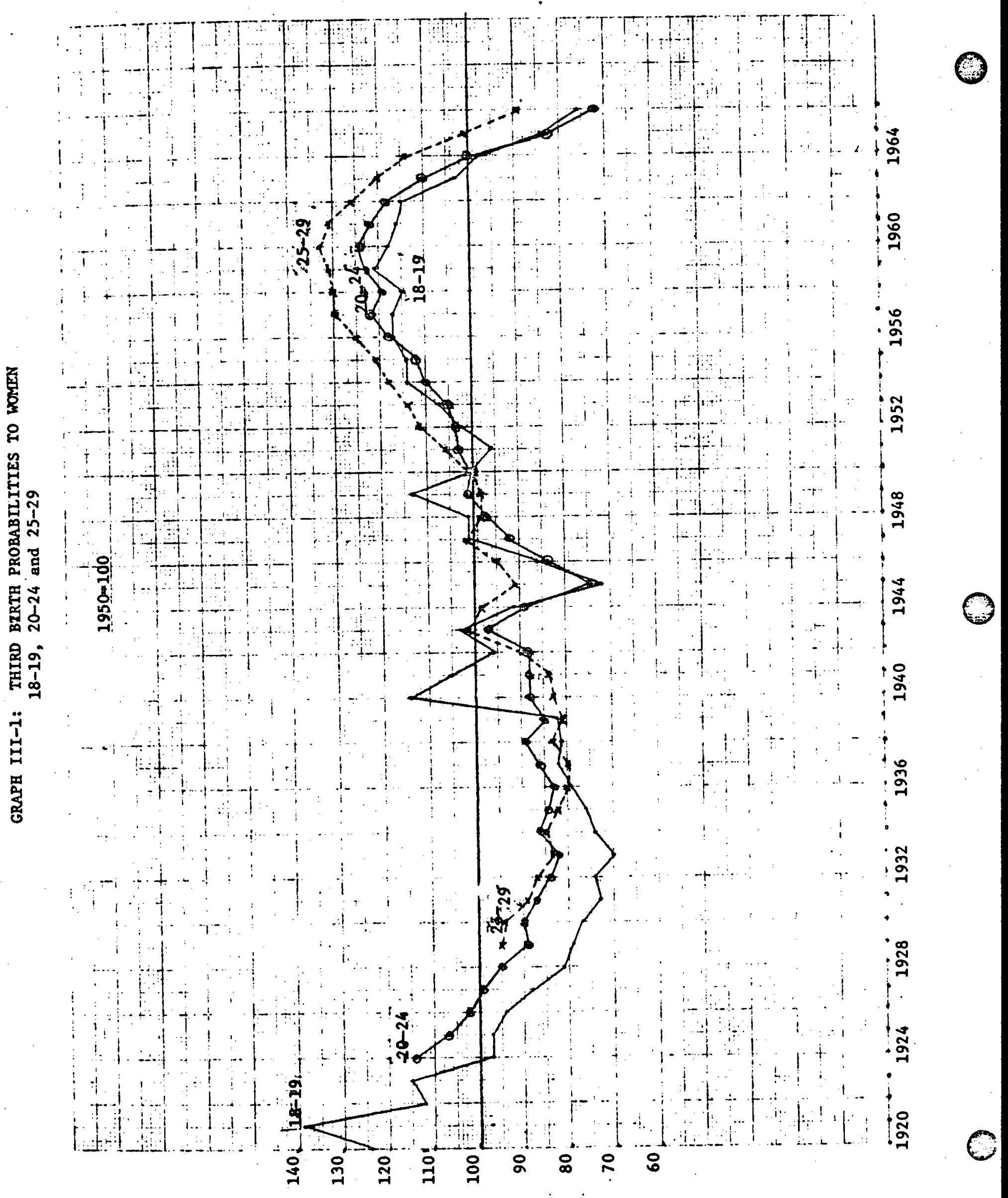




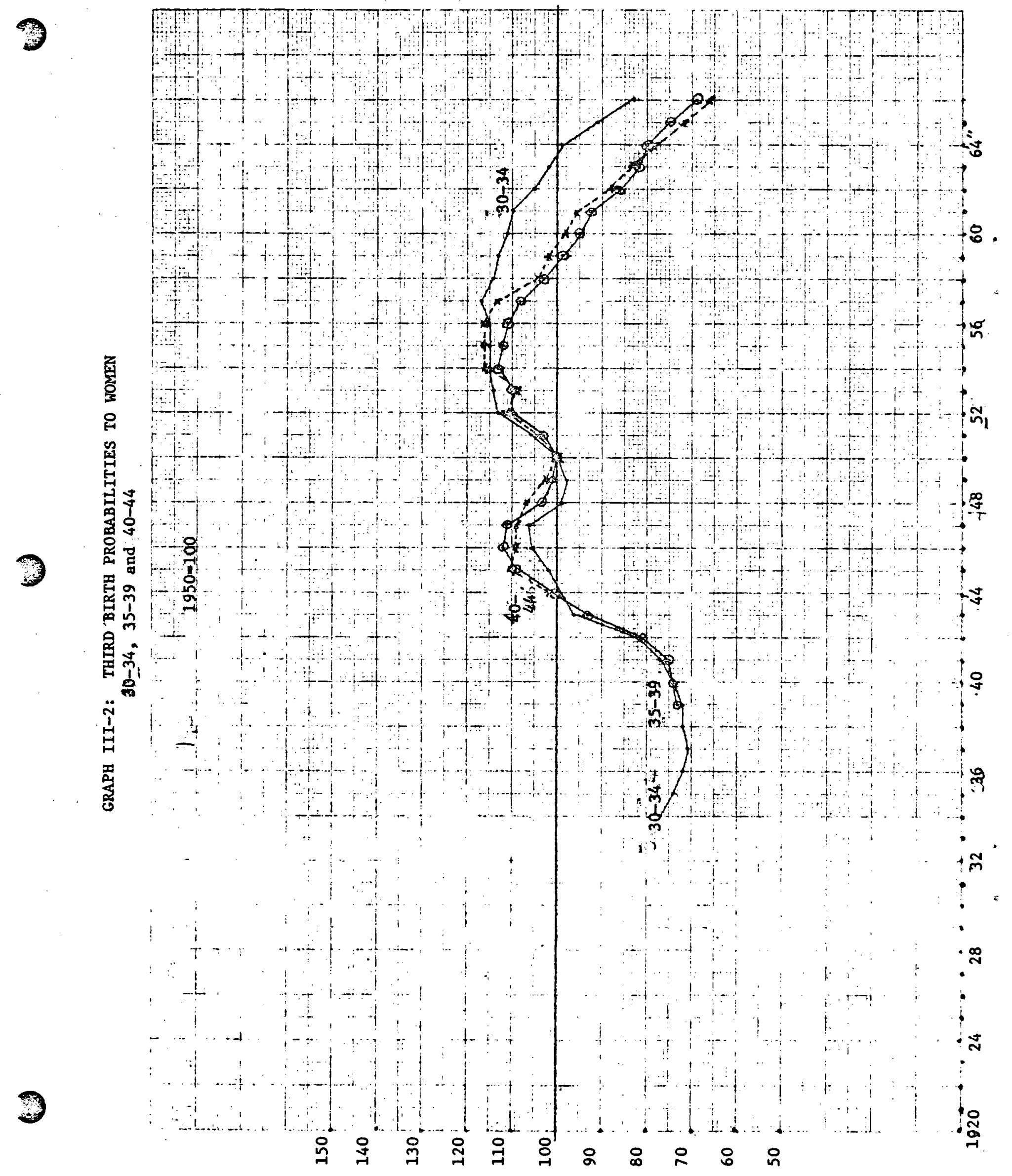




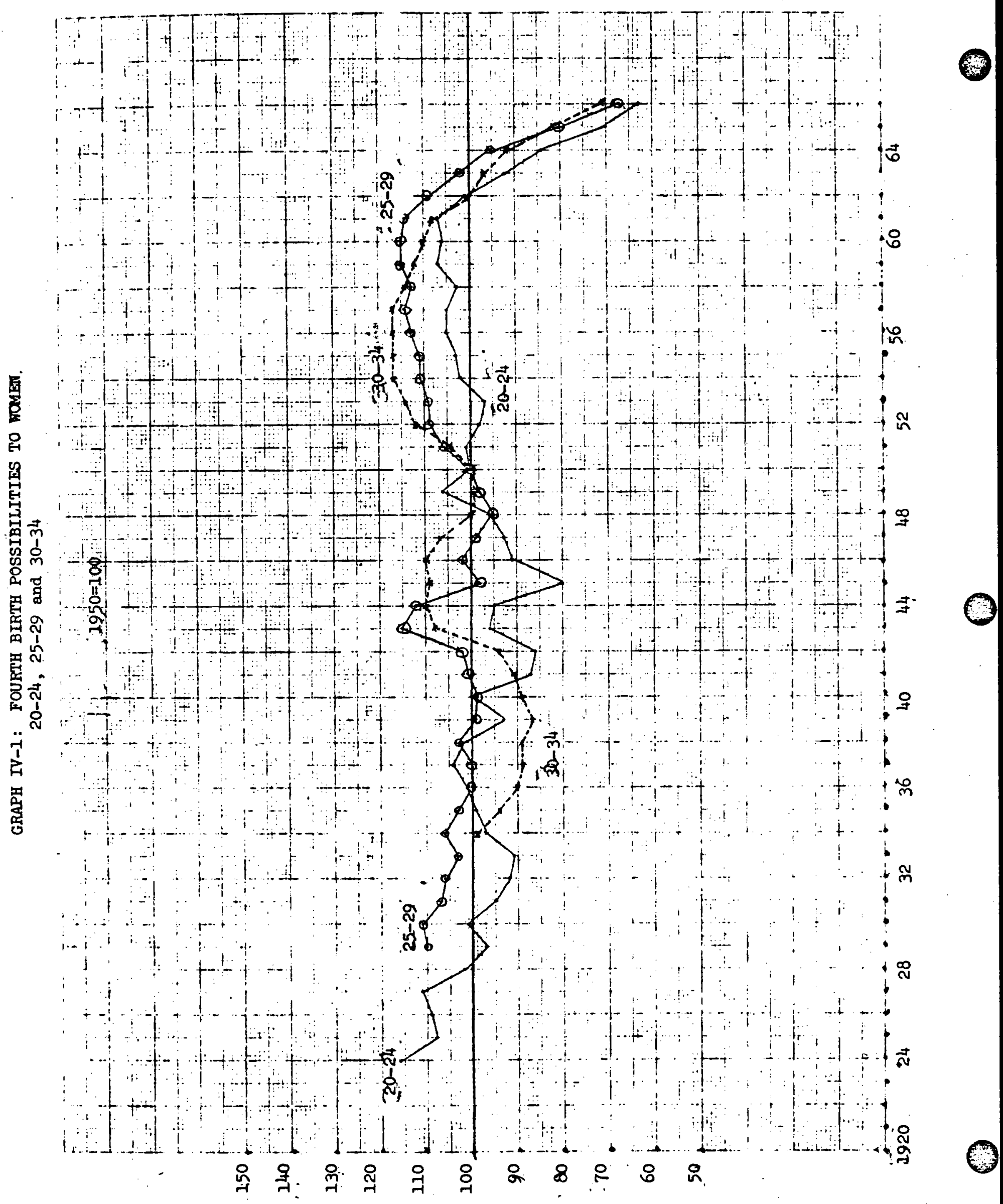




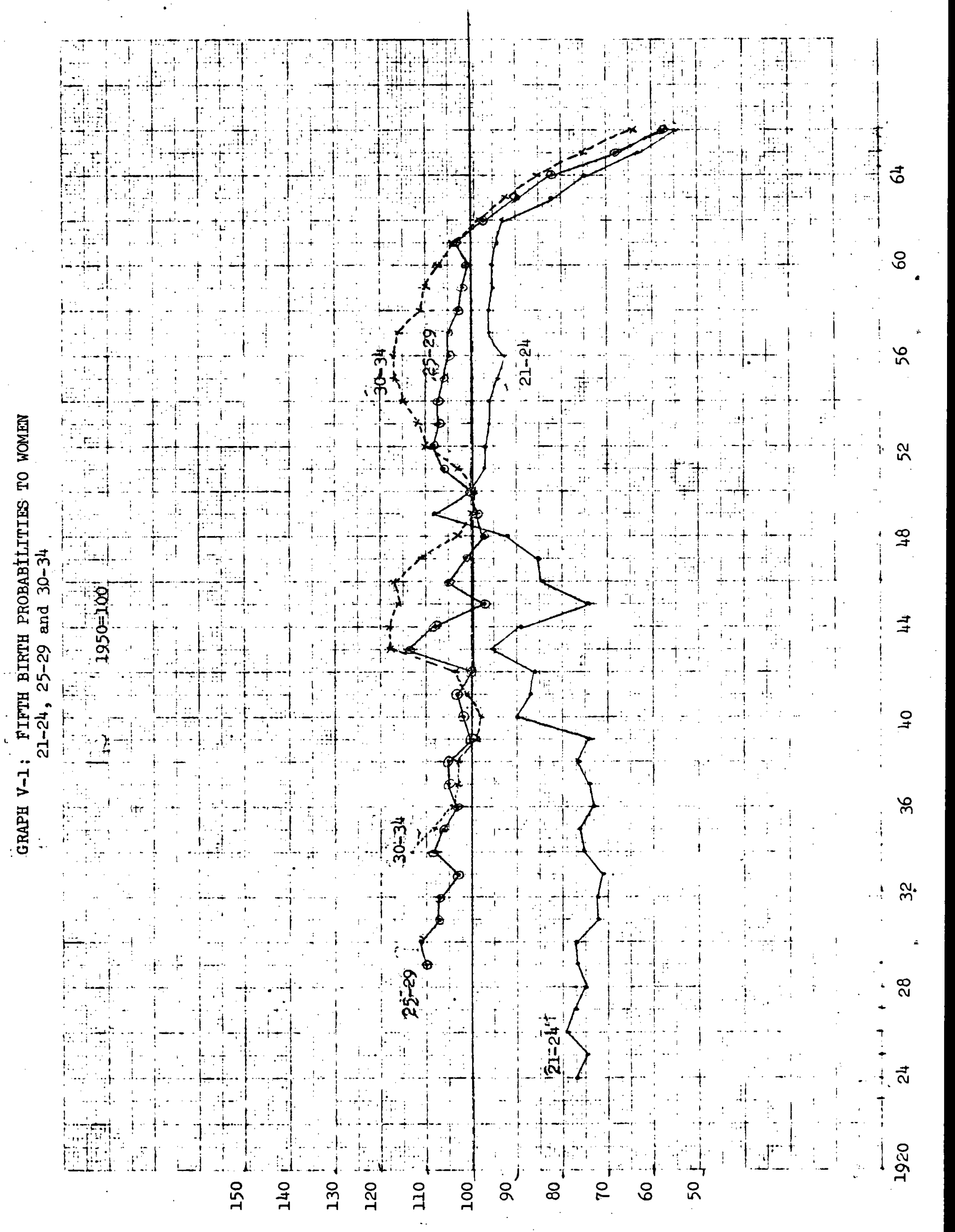




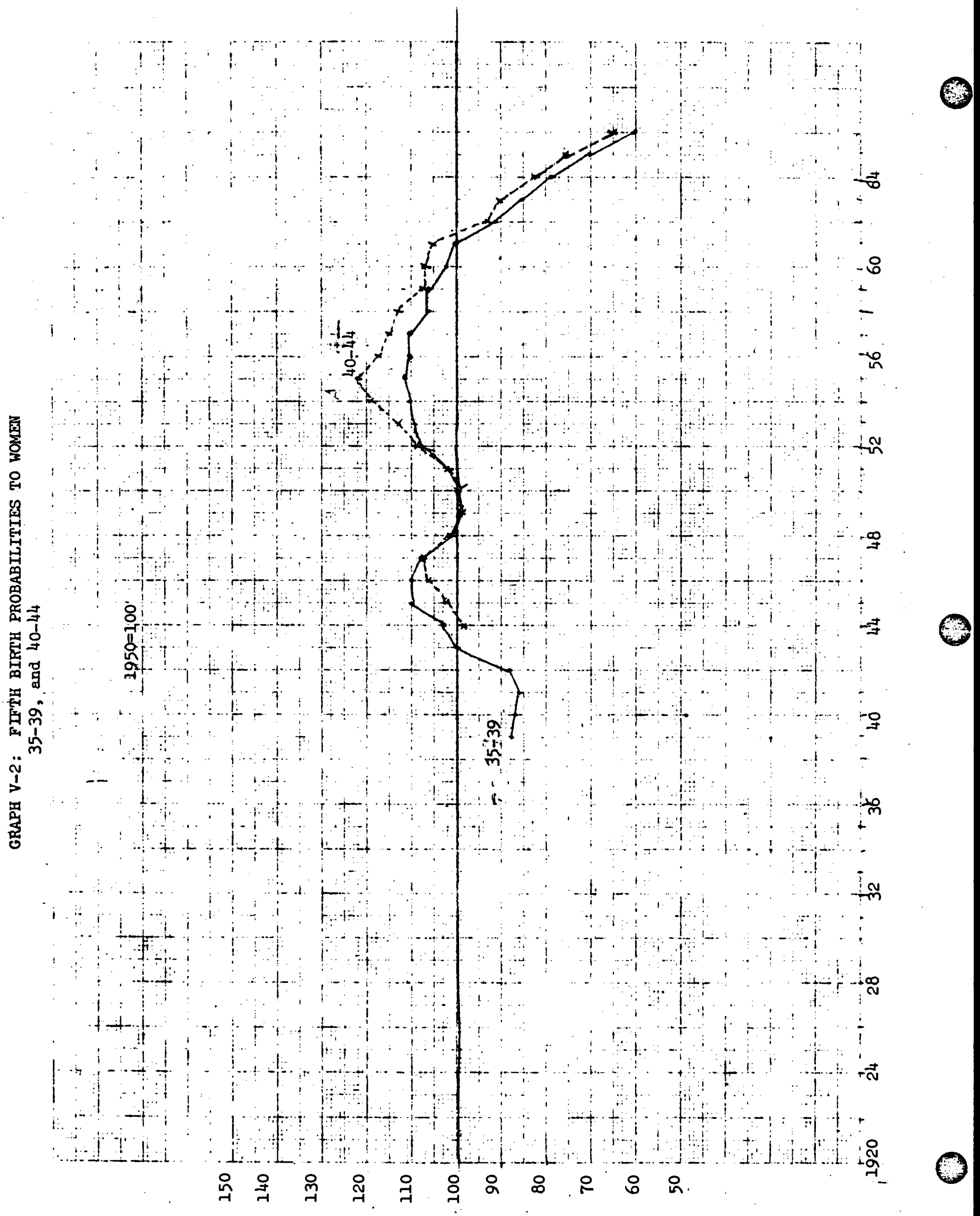




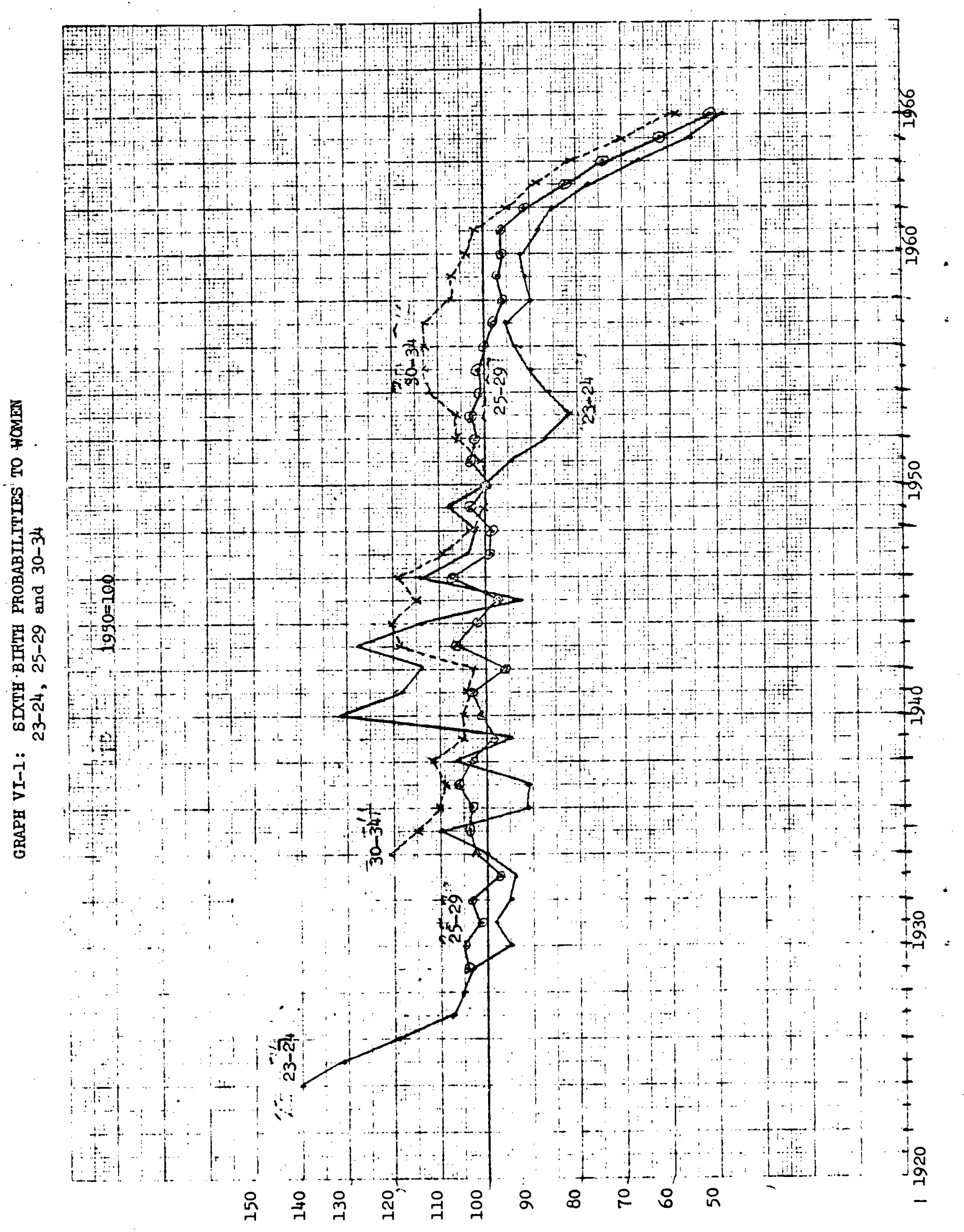




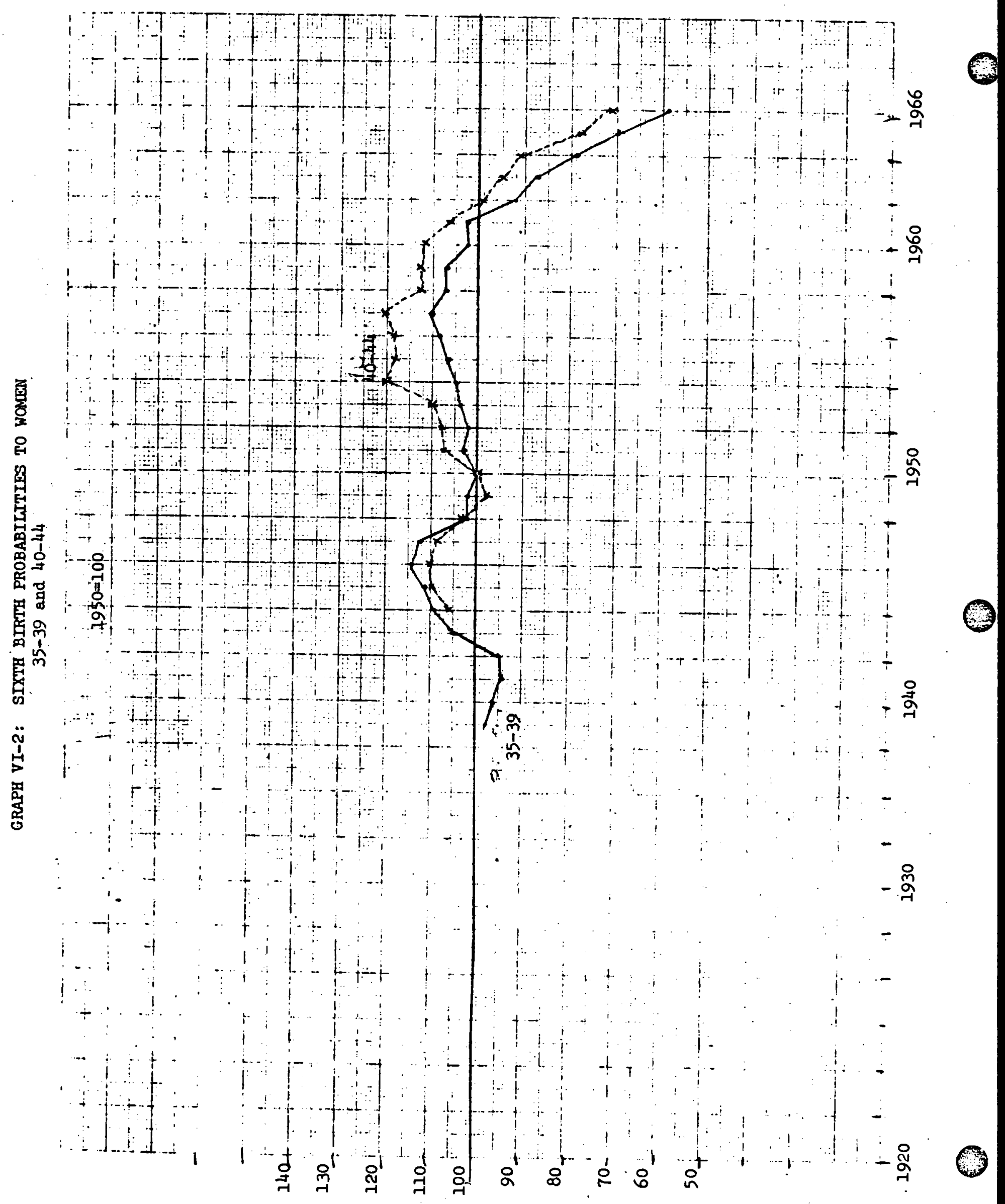




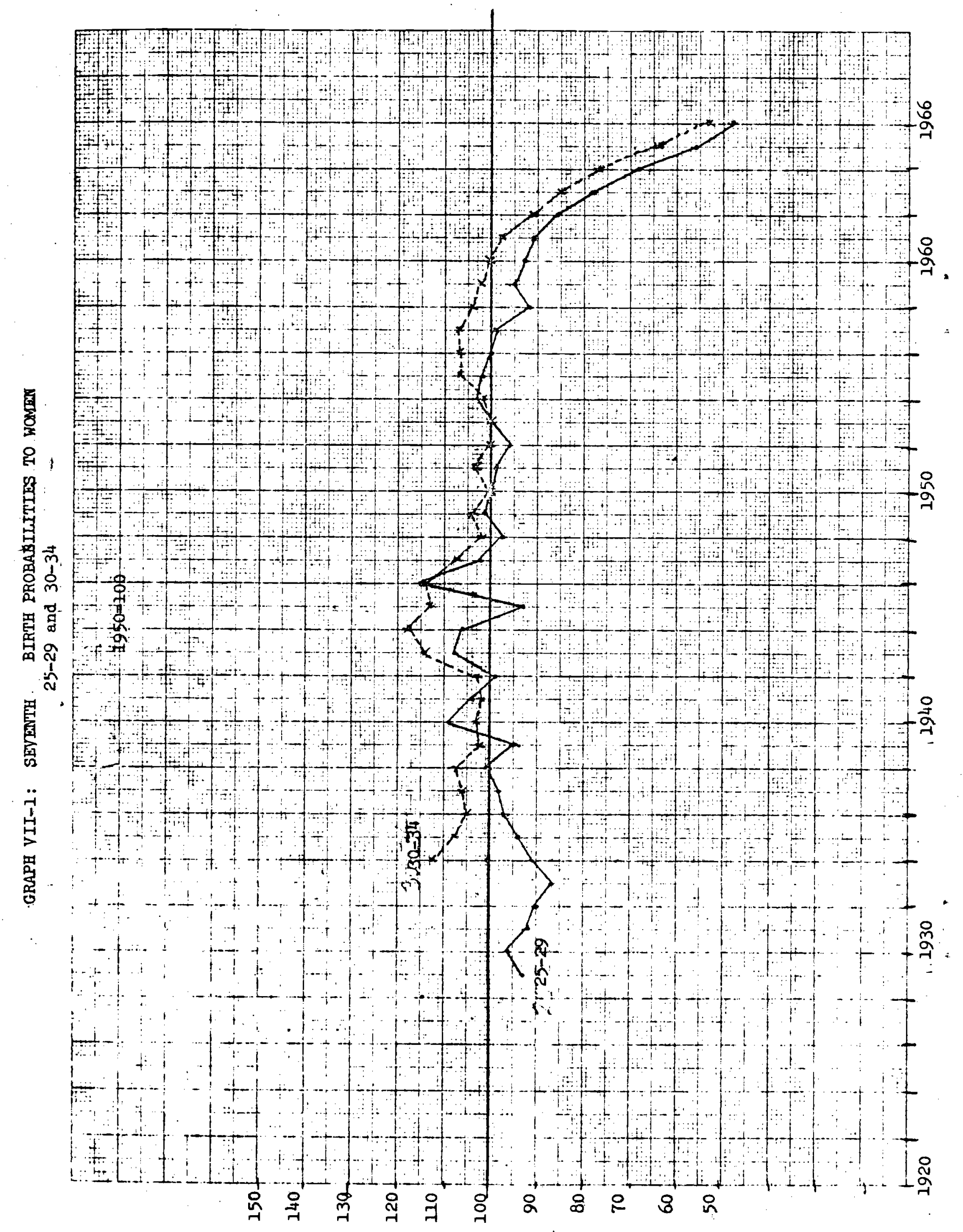




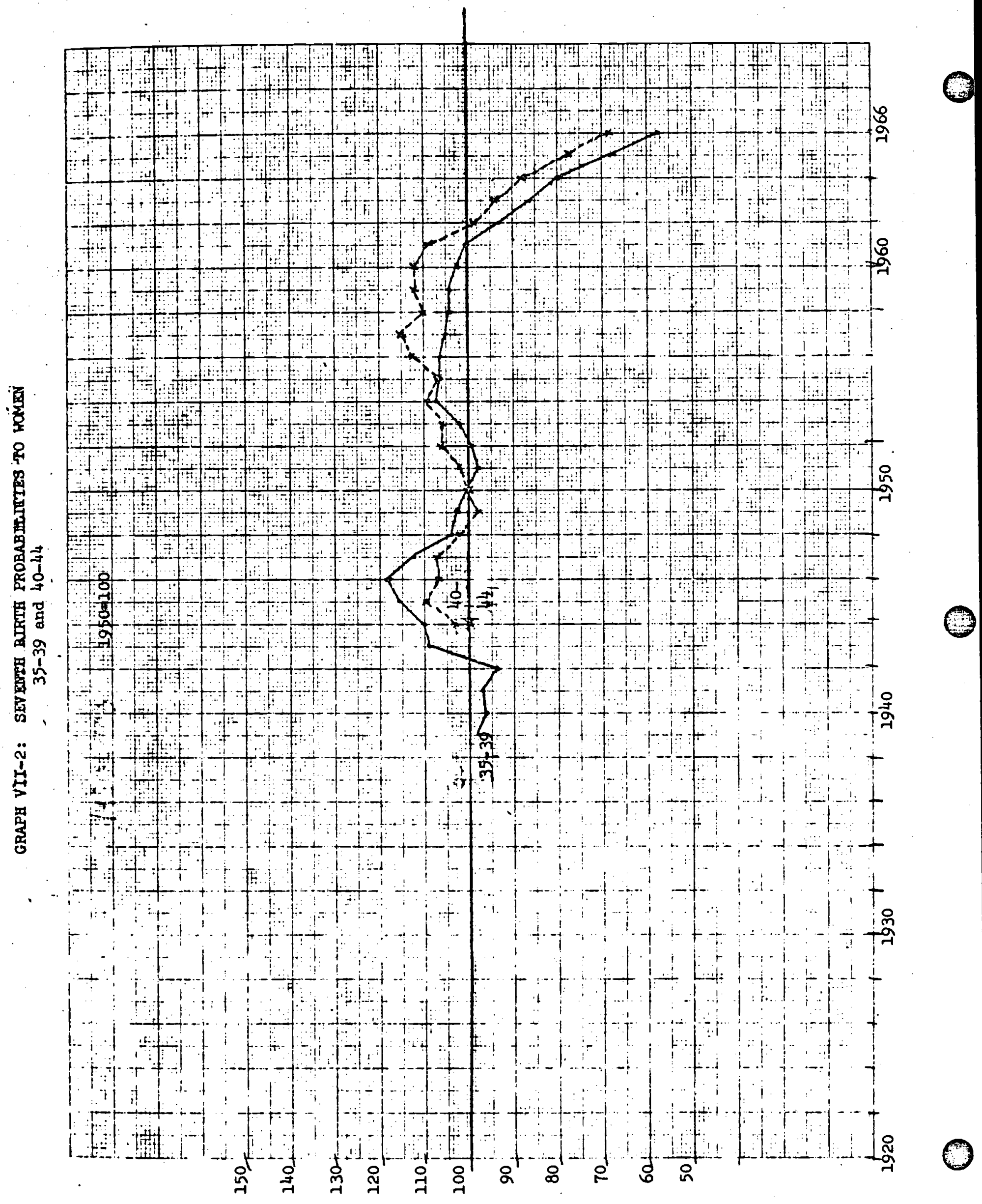




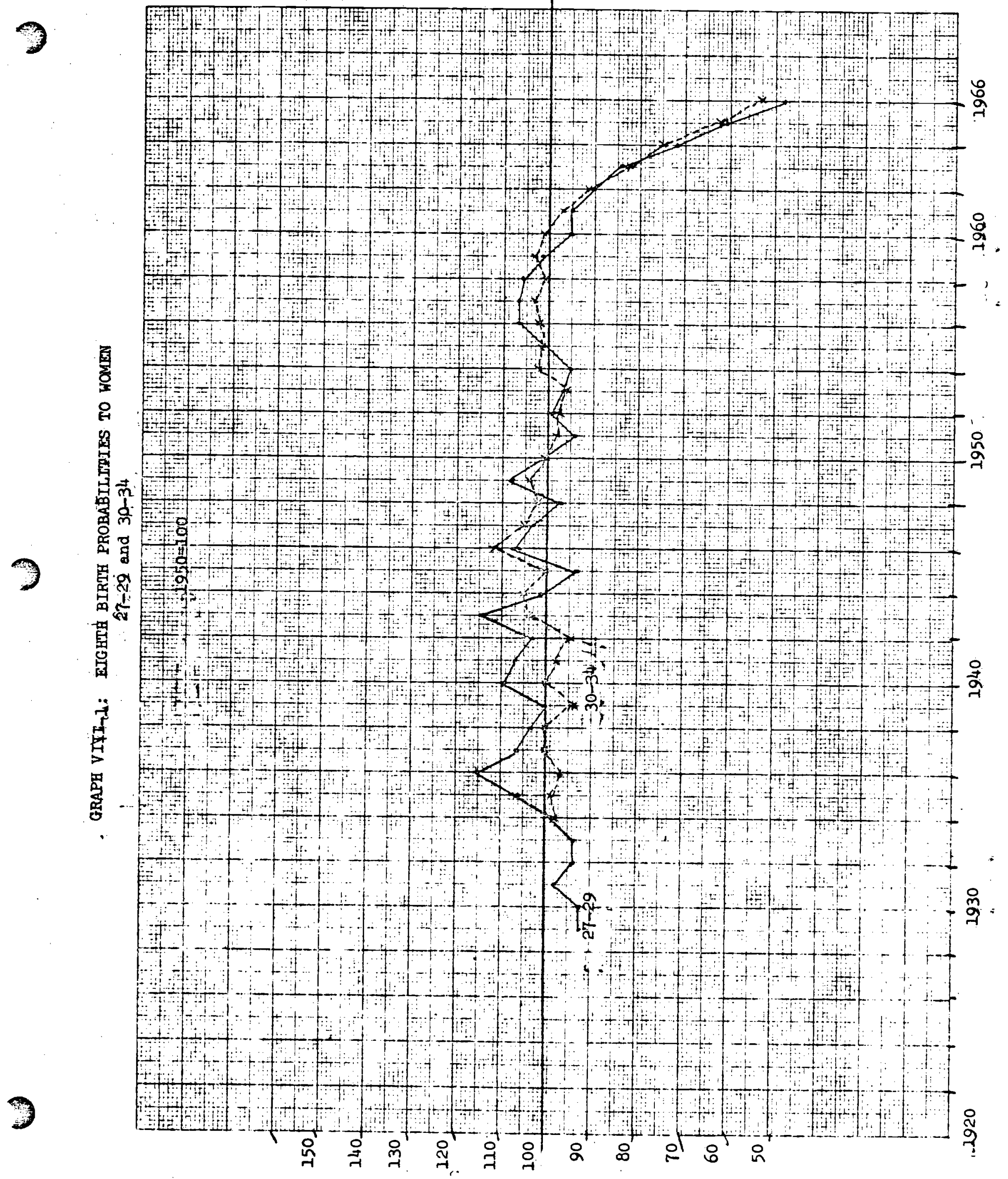




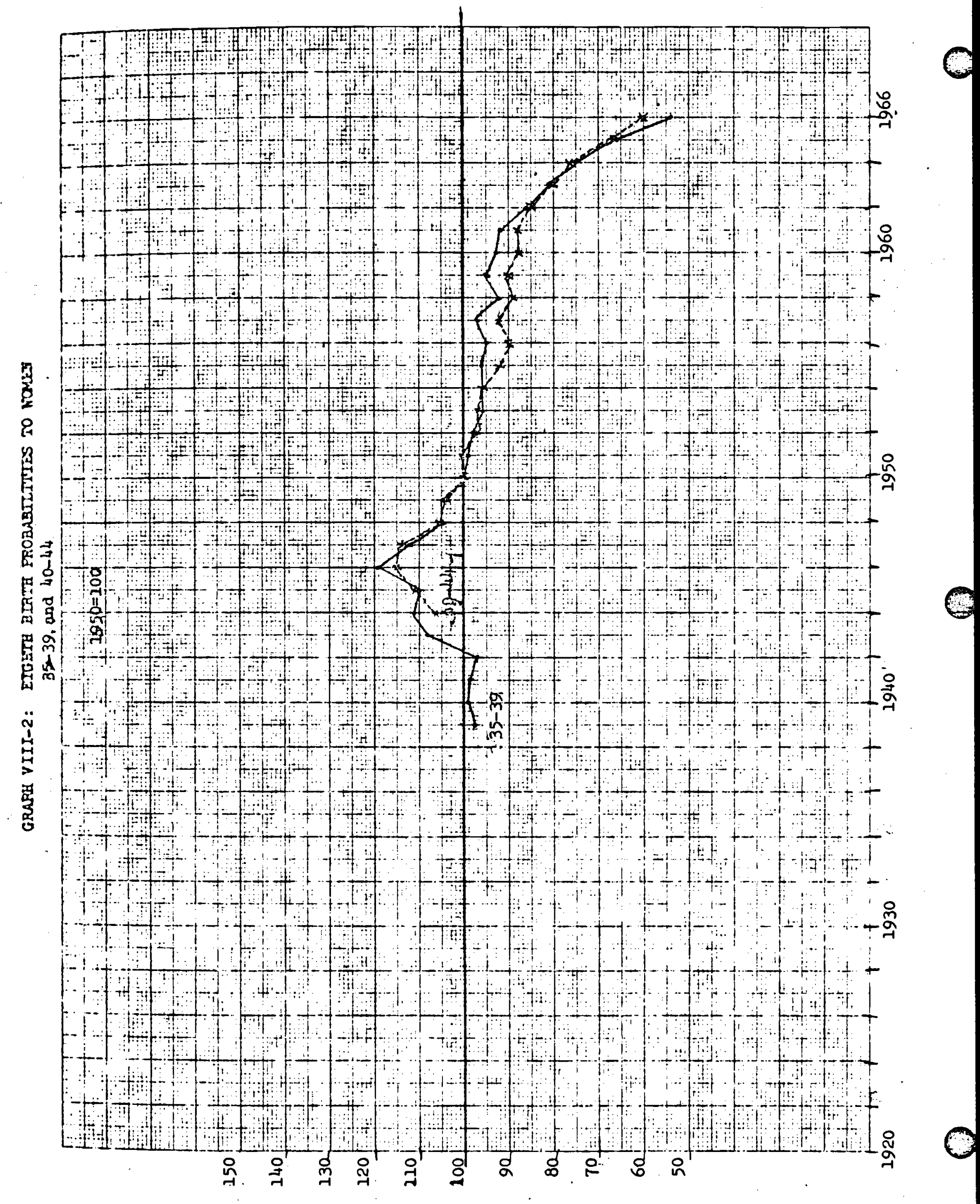


3

3

APPENDIX III

4

- APPENDIX III

3 
$T A R L E \quad A-1$

THE MENTHLY PQLBBABILITY (IN PERCENT) OF HAVINC A BIRTH NATIVE WHITE WOMEN, 1420-1966, FDR SELECTED AGE GROUPS

FIRST BIRTHS

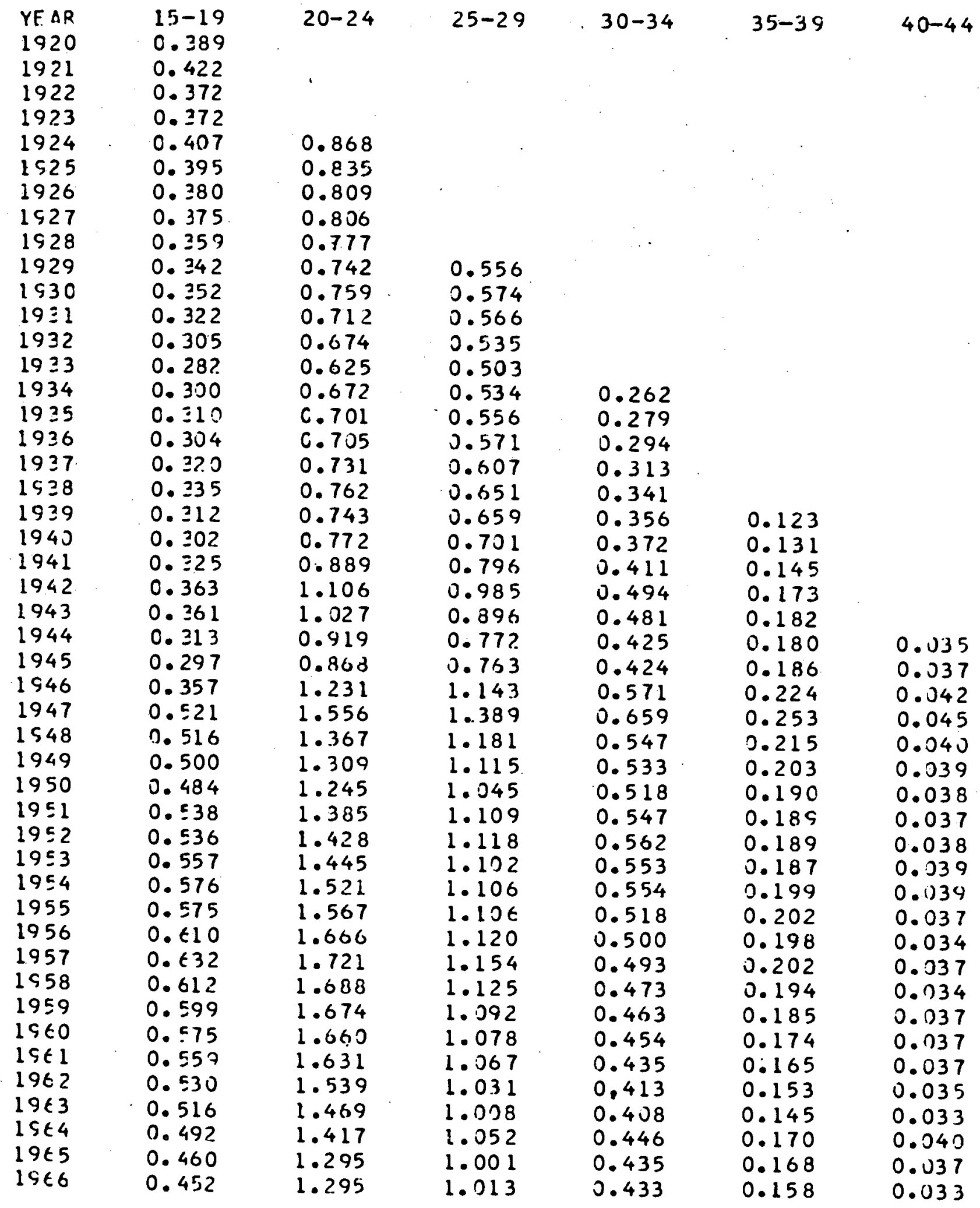




$$
-2-
$$

TABLE A-1

THE MONTHLY PRIBABILITY (IN PERCENT) UF HAVING A BIRTH NATIVE WHITE NOMEN, 1920-1960, FOR SELECTFD ACF GPOUPS SECOND BIRTHS

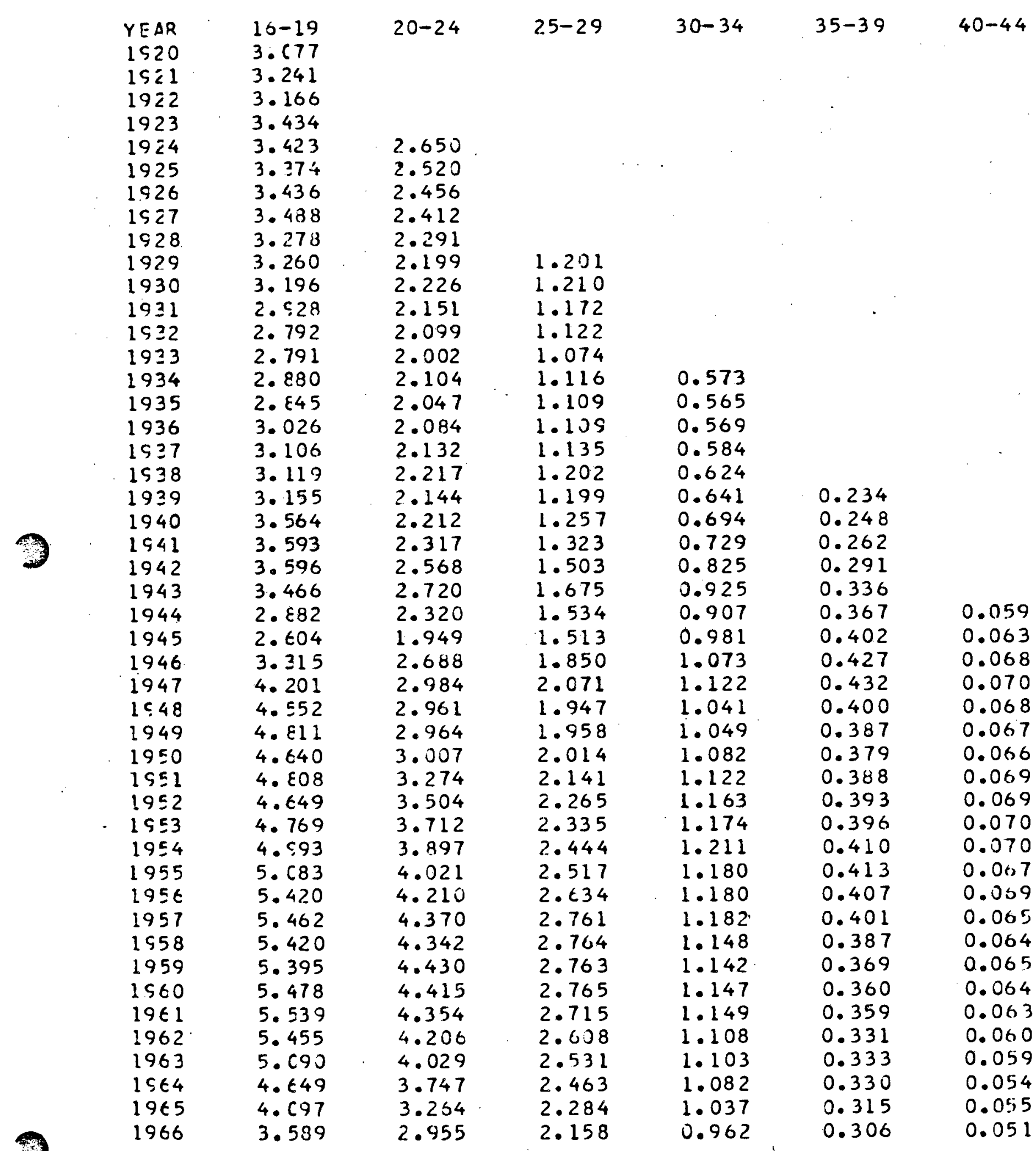


TARLE A-1

THE MINNTLLY PROEAEILITY (INI PERCENT) OF HAVING A BIRTH NATIVF WHITE WOMEN, 1920-1966, FOR SELFC.TEO AGF GRIJUPS THIR.D BIRTHS

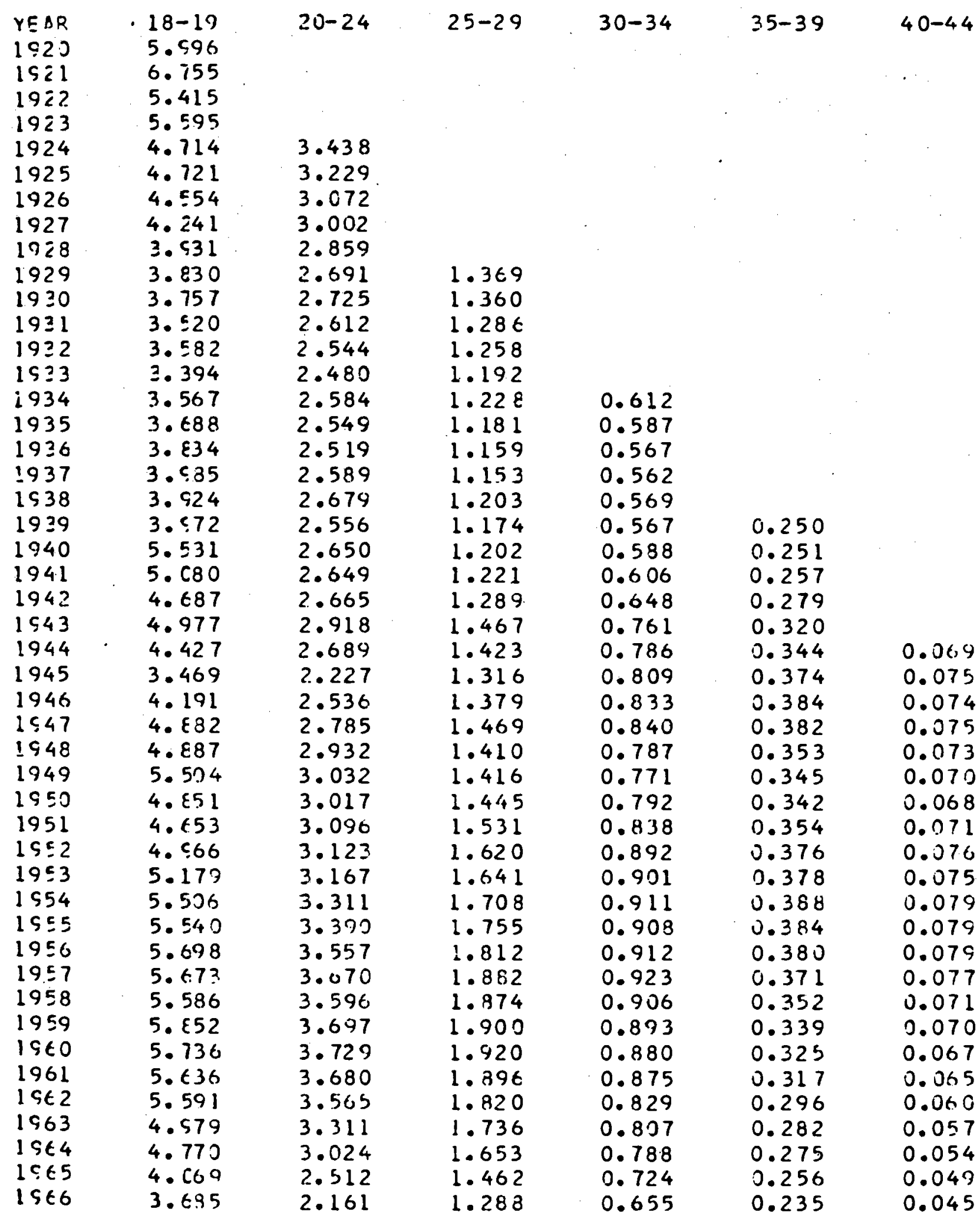


TARLE A-1

THF MCNTHLY PRORABILITY (IN PFRCFNT) DF HAVING A BIRTH NAT IVE WHITE WOMEN, 1920-1966, FUR SELECTED AGF GROUPS FOURTH BIRTHS

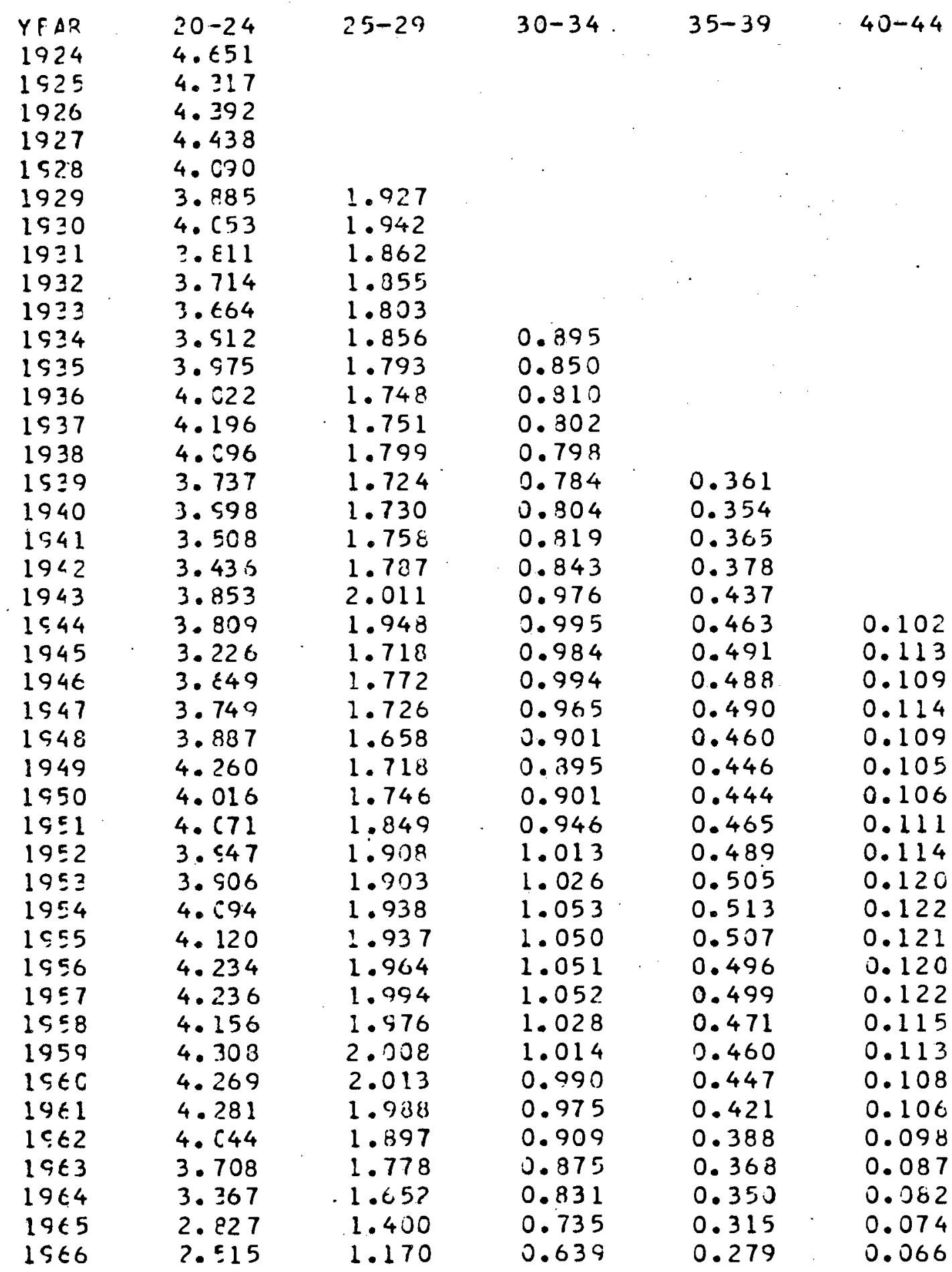


TARLF $A-1$

THE MONTHLY PREBABILITY (IN PFRCENT) RF HAVING A BIRTH MAT IVE WHITE WOMEN, 192:-1966, FOR SELECTEO AG? GRNUPS FIFTH BIRTHS

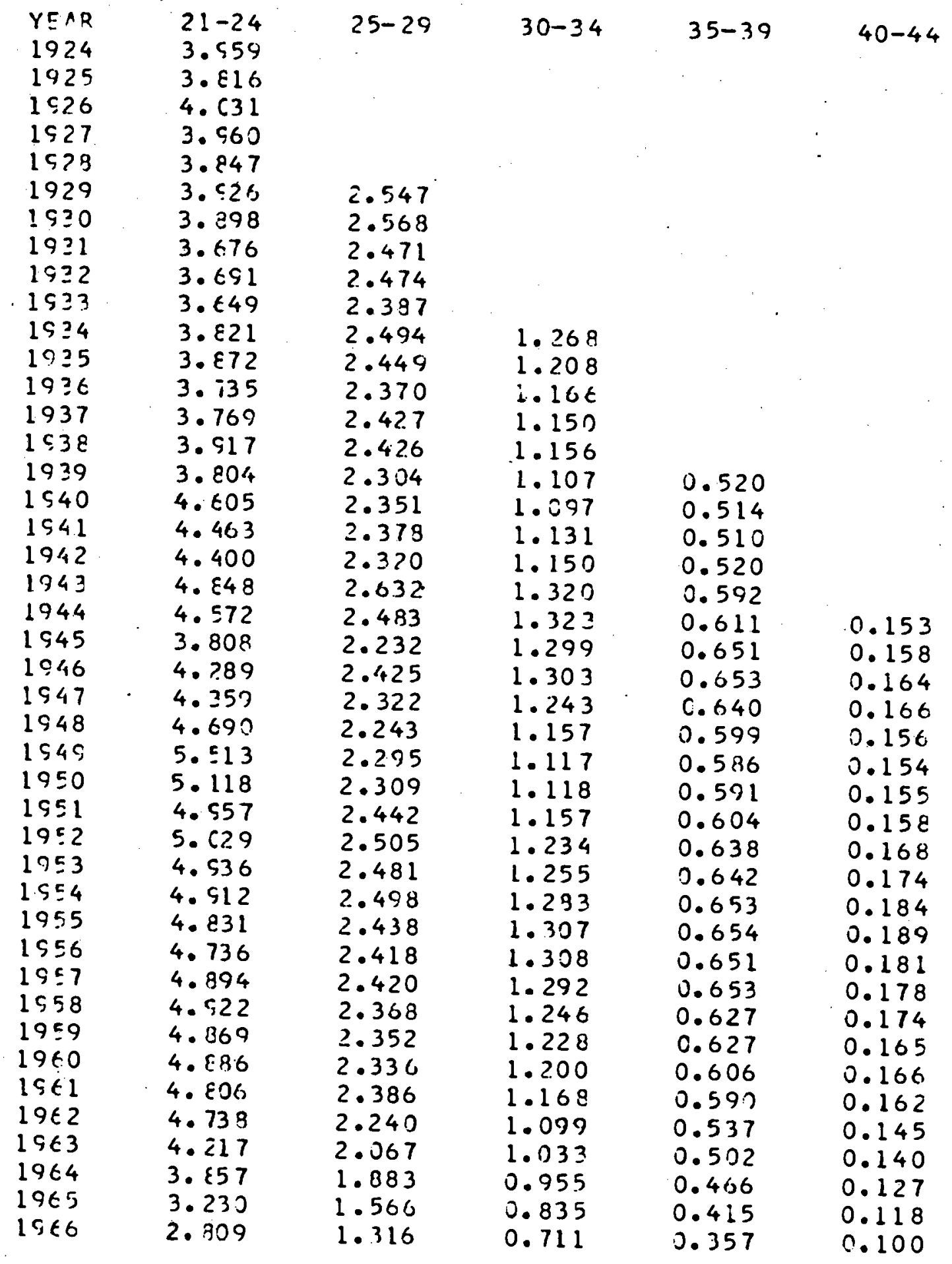


TABLE A-1

THF MONTHLY PROQARILITY (IN PERCENT) CF HAVINC A BIRTH NATIVE WHITE ACMEN, 13? J-1366, FOR SELECTED AG GROUPS SIXTH BIRTHS

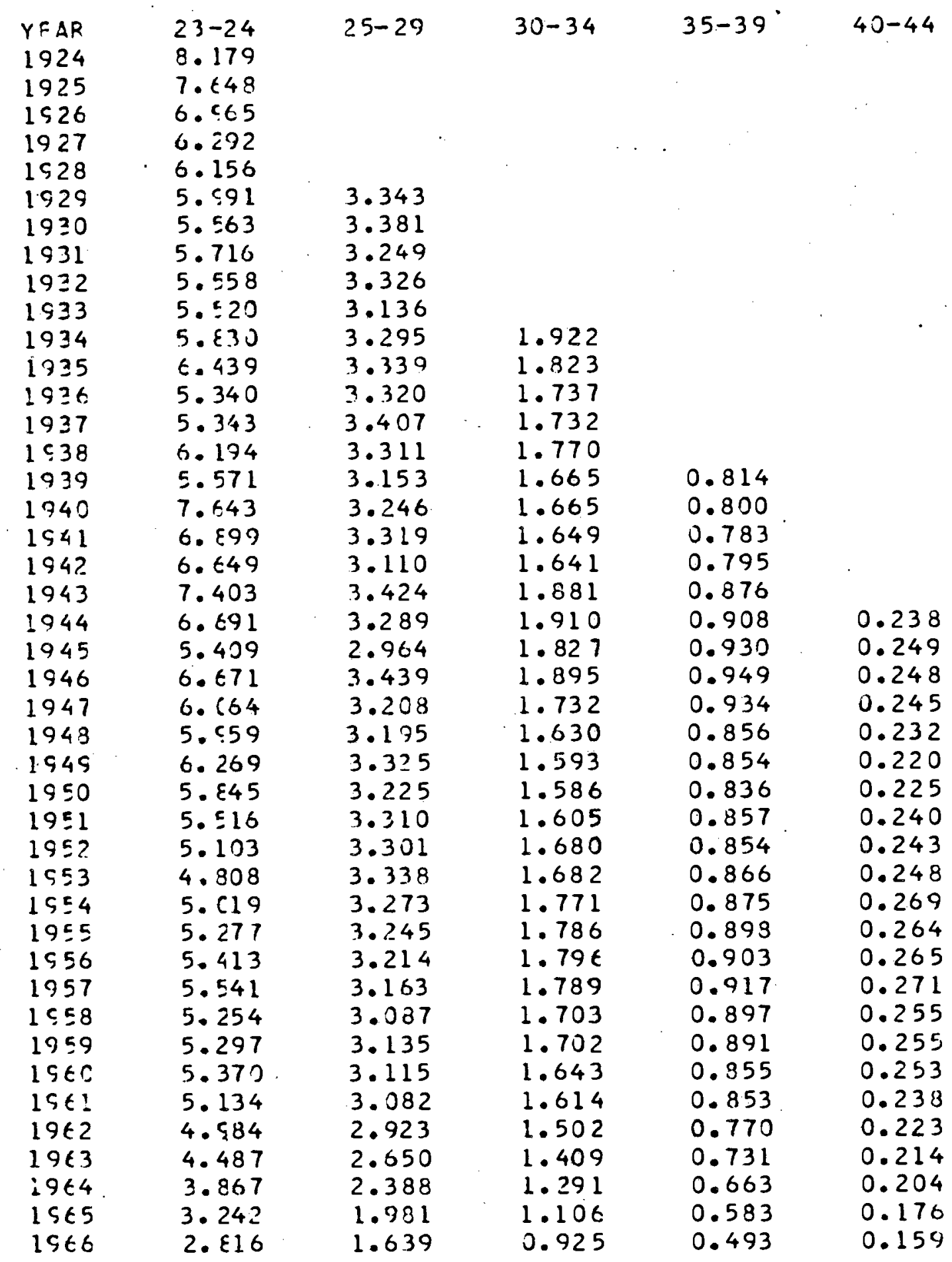


$T A B L F A-1$

THE MCNTHLY PROEA3IL!TY (IN PERCENT) OF HAVINC A BIRTH NATIVE WHITE WONEN, 1\$20-1966, FUR SELECTED AGF. GRTUPS SEVFNTH PIRTHS

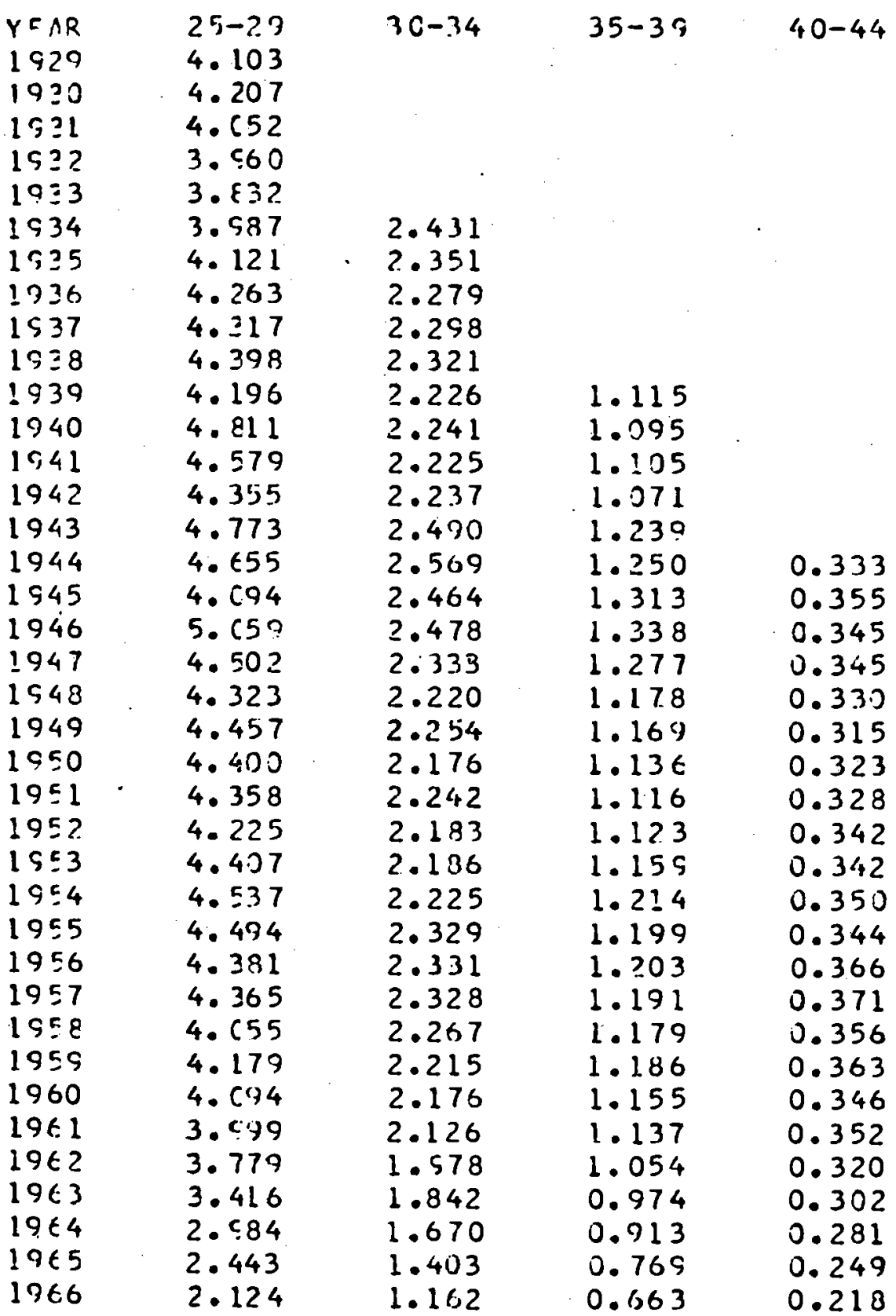


TARLE $A-1$

THE MOPITHLY PRIBABILITY (IN PERCENT) TIF HAVING A BIRTH NATIVE WHITE WJIAEN, 192J-1966, FOR. SELECTED $\triangle G$ : GROUPS FIGHTH+ BIRTHS

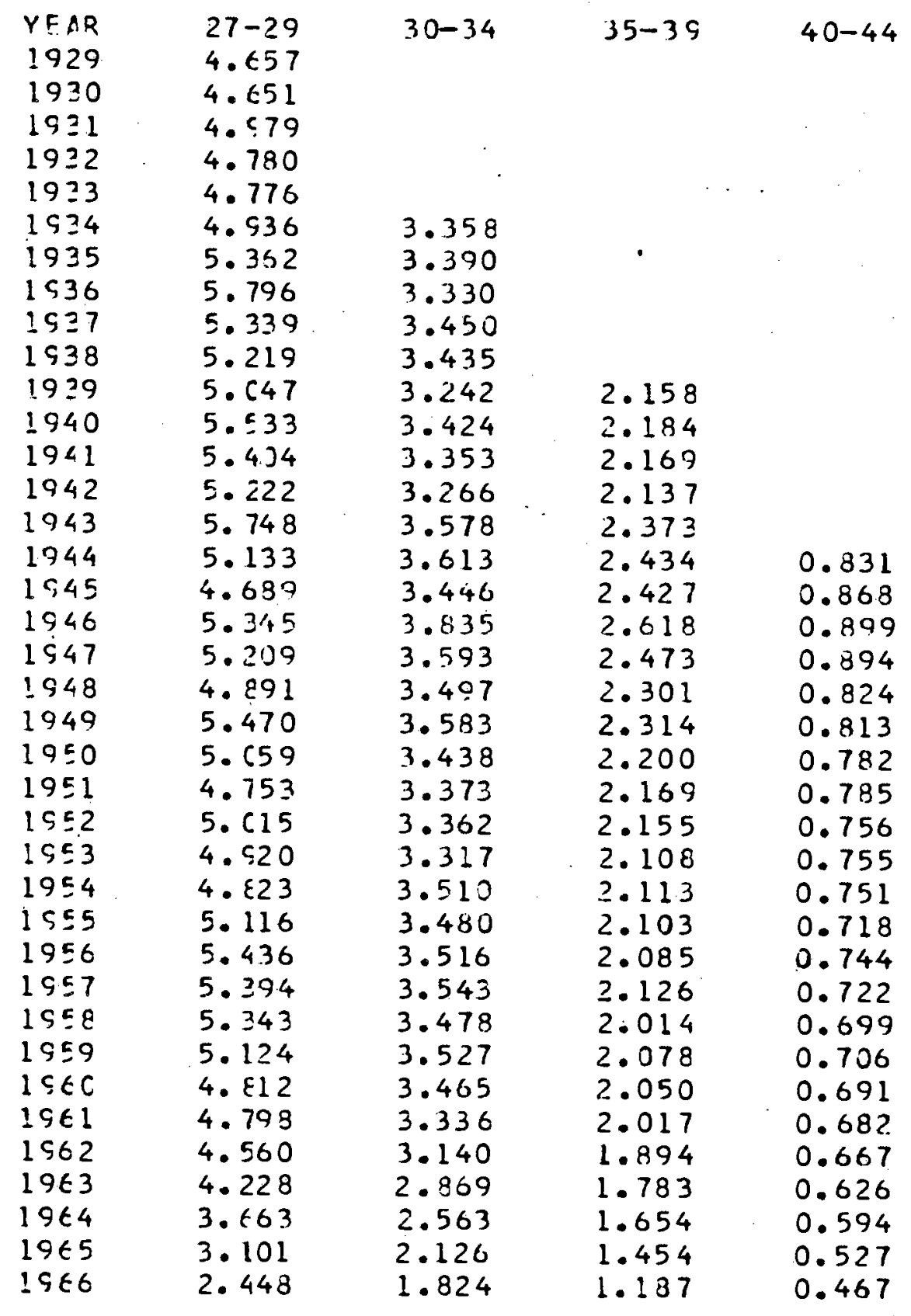


TABLE A-2

Age Coefficients From Component Decomposition Analysis

\begin{tabular}{|c|c|c|c|c|}
\hline Age & First Births & Second Births & Third Births & Fourth Births \\
\hline $\begin{array}{l}18 \\
19 \\
20\end{array}$ & $\begin{array}{l}-59.810 \\
-54.489 \\
-49.382\end{array}$ & $\begin{array}{l}-47.666 \\
-43.633 \\
-39.667\end{array}$ & $\begin{array}{l}-51.294 \\
-46.989 \\
-42.729\end{array}$ & $\begin{array}{l}\text { n.a. } \\
\text { n.a. } \\
\text { n.a. }\end{array}$ \\
\hline $\begin{array}{l}21 \\
22 \\
23 \\
24 \\
25\end{array}$ & $\begin{array}{l}-44.323 \\
-39.295 \\
-34.293 \\
-29.332 \\
-24.402\end{array}$ & $\begin{array}{l}-35.710 \\
-31.743 \\
-27.754 \\
-23.774 \\
-19.799\end{array}$ & $\begin{array}{l}-38.454 \\
-34.195 \\
-29.898 \\
-25.636 \\
-21.388\end{array}$ & $\begin{array}{c}\text { n.a. } \\
-33.652 \\
-29.409 \\
-25.196 \\
-21.029\end{array}$ \\
\hline $\begin{array}{l}26 \\
27 \\
28 \\
29 \\
30\end{array}$ & $\begin{array}{l}-19.480 \\
-14.608 \\
-9.718 \\
-4.875 \\
0.000 *\end{array}$ & $\begin{array}{l}-15.843 \\
-11.863 \\
-7.880 \\
-3.951 \\
0.000 \star\end{array}$ & $\begin{array}{r}-17.125 \\
-12.859 \\
-8.551 \\
-4.295 \\
0.000 \star\end{array}$ & $\begin{array}{r}-16.838 \\
-12.654 \\
-8.414 \\
-4.232 \\
0.000 *\end{array}$ \\
\hline $\begin{array}{l}31 \\
32 \\
33 \\
34 \\
35\end{array}$ & $\begin{array}{r}4.775 \\
9.620 \\
14.400 \\
19.232 \\
24.045\end{array}$ & $\begin{array}{r}3.871 \\
7.801 \\
11.660 \\
15.541 \\
19.409\end{array}$ & $\begin{array}{r}4.203 \\
8.501 \\
12.723 \\
16.967 \\
21.198\end{array}$ & $\begin{array}{r}4.139 \\
9.397 \\
12.581 \\
16.784 \\
20.976\end{array}$ \\
\hline $\begin{array}{l}36 \\
37 \\
38 \\
39\end{array}$ & $\begin{array}{l}28.812 \\
33.578 \\
38.342 \\
43.010\end{array}$ & $\begin{array}{l}23.220 \\
27.039 \\
30.857 \\
34.573\end{array}$ & $\begin{array}{l}25.391 \\
29.575 \\
33.766 \\
37.853\end{array}$ & $\begin{array}{l}25.142 \\
29.293 \\
33.452 \\
37.507\end{array}$ \\
\hline
\end{tabular}

n.a. = not applicable

* = by assumption. 
TABLF $A-3$

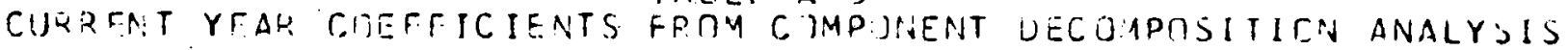

3

\begin{tabular}{|c|c|c|c|c|}
\hline YEAR & FIRST BIRTHS & SFCINNI) BIRTHS & THIRD BIRTHS & FOURTH AIRTHS \\
\hline 1920 & 199.432 & 162.468 & 176.214 & N.A. \\
\hline 1921 & 194.473 & 153.457 & 171.876 & A.A. \\
\hline 1922 & 189.348 & 154.353 & 167.300 & $N \cdot A$. \\
\hline 1923 & 184.307 & 150.293 & 162.398 & $N . A$. \\
\hline 1924 & 179.355 & 146.223 & 158.479 & $N \cdot A$. \\
\hline 1.925 & 114.307 & 142.098 & 154.050 & 152.004 \\
\hline 1936 & 169.270 & 137.983 & 149.602 & 147.651 \\
\hline 1327 & 164.262 & 133.877 & 145.165 & 143.323 \\
\hline 1328 & 159.219 & 129.741 & 240.701 & 138.920 \\
\hline 1429 & 154.176 & 125.617 & 136.242 & 134.519 \\
\hline 1330 & 149.212 & 121.556 & 131.842 & 130.197 \\
\hline 1931 & 144.176 & 117.437 & 127.385 & 125.806 \\
\hline 1932 & 139.135 & 113.323 & 122.956 & 121.447 \\
\hline 1933 & 134.070 & 103.195 & 118.507 & 117.066 \\
\hline 1934 & 129.149 & 105.167 & 114.131 & 112.747 \\
\hline 1935 & 124.209 & 101.087 & 109.106 & 108.367 \\
\hline 1936 & 119.243 & 97.025 & 105.286 & 103.588 \\
\hline 193.7 & 114.300 & 92.971 & 100.885 & 99.634 \\
\hline 1938 & 109.357 & 88.951 & 96.494 & 95.249 \\
\hline 1939 & 104.335 & 84.889 & 42.082 & 90.920 \\
\hline 1940 & 99.435 & 80.877 & 87.736 & 86.557 \\
\hline 1941 & 94.558 & 76.854 & 83.341 & 82.273 \\
\hline 1342 & $N \cdot A$. & $N \cdot A$ & N.A. & $N \cdot A$. \\
\hline 1943 & $N . A$. & N.A. & N.A. & $N \cdot A$. \\
\hline 1944 & $N . \Delta$. & N.A. & $N . A$. & $N . A$. \\
\hline 1945 & $N . A$. & N.A. & $N . A$. & $N . A$. \\
\hline 1945 & N. 1. & N.A. & $N . A$. & $N . A$. \\
\hline 1947 & N.A. & N.A. & $N . A$. & $A-A$. \\
\hline 1948 & 60.031 & 48.704 & 52.710 & 51.952 \\
\hline 1949 & 54.942 & 44.627 & 48.314 & $47 . t 25$ \\
\hline 1951 & 49.051 & 40.567 & 43.907 & 43.290 \\
\hline 1951 & 45.020 & 36.546 & 39.538 & 39.000 \\
\hline 1957 & 40.045 & 32.514 & 35.183 & 34.703 \\
\hline 1953 & 35.043 & 28.467 & 30.791 & 30.378 \\
\hline 1954 & 30.071 & 24.427 & 26.420 & 26.066 \\
\hline 1955 & 25.063 & 20.363 & 22.024 & 21.725 \\
\hline 1956 & 20.070 & 16.313 & 17.637 & 17.391 \\
\hline 1957 & 15.088 & 12.258 & 13.247 & 13.064 \\
\hline 1958 & 10.053 & 8.165 & 8.819 & 8.648 \\
\hline 1959 & 5.026 & 4.081 & 4.415 & 4.352 \\
\hline 1960 & 0.000 & 0.000 & 0.000 & $C \cdot C 00$ \\
\hline 1961 & -5.033 & -4.081 & -4.418 & -4.366 \\
\hline 1702 & -10.087 & -8.198 & -8.868 & -8.770 \\
\hline 1963 & -15.120 & -12.292 & -13.326 & -13.165 \\
\hline 1.734 & $-20.06 l$ & -16.397 & -17.779 & -17.570 \\
\hline 1965 & -25.106 & -20.548 & -22.306 & -22.047 \\
\hline 1966 & -30.119 & -24.684 & -26.827 & -26.531 \\
\hline
\end{tabular}


IABLE A-4

G MRIFT REEFICICNTS FRCM COMPONENT DECIMPOSITION ANALYSIS

\begin{tabular}{|c|c|c|c|c|}
\hline$\cdots 1$ & PIRST RIPTHS & SECIINSD HIRTHS & THIRD BIPTHS & FOUKTH UIRTHS \\
\hline 1111 & -154.0 .97 & -126.207 & -136.445 & -134.480 \\
\hline$i \cdot 3 l$ & -14.1 .743 & -122.193 & -132.088 & -130.200 \\
\hline (1)! & $-14 \% .76,1$ & -118.139 & -127.710 & -125.390 \\
\hline 1113 & -134.759 & -114.073 & -123.320 & -121.548 \\
\hline 1116 & -134.740 & -104.585 & -113.914 & -117.193 \\
\hline 1.175 & -129.703 & -105.912 & -114.538 & -1.12 .863 \\
\hline 100 & -124.701 & -101.830 & -110.134 & -108.455 \\
\hline 1101 & -119.728 & -97.752 & -105.731 & -104.175 \\
\hline 12$) 8$ & -114.742 & -93.676 & -101.327 & -99.829 \\
\hline$(+2)$ & -109.764 & -89.595 & -96.920 & -95.444 \\
\hline $1 \cdot 21 \cdot 1$ & -104.758 & -35.492 & $-92 \cdot 480$ & -91.076 \\
\hline $1 \cdot 11$ & -99.772 & -81.412 & -88.068 & -86.720 \\
\hline $1 \% 12$ & -94.731 & -77.353 & -83.676 & -82.375 \\
\hline 1913 & -80.808 & -73.26 .5 & -79.242 & $-78 \cdot C 28$ \\
\hline 1114 & -84.851 & -69.209 & -74.833 & -73.682 \\
\hline $11 / 5$ & -79.876 & -65.147 & -70.428 & -69.338 \\
\hline 1.116 & -74.904 & -61.072 & -66.021 & -64.568 \\
\hline 1717 & -69.939 & -57.017 & -61.610 & -60.660 \\
\hline 1218 & -64.919 & -52.918 & -57.203 & -56.334 \\
\hline 1.117 & -59.838 & -48.831 & -52.824 & -52.052 \\
\hline 1922 & -54.853 & -44.737 & -48.429 & -47.707 \\
\hline 1921 & -49.921 & -40.764 & -44.026 & -43.366 \\
\hline $192 \%$ & -44.931 & -36.702 & -39.638 & -39.043 \\
\hline $1+23$ & -39.922 & -32.626 & -35.230 & -34.725 \\
\hline 1424 & $\cdot-34.957$ & -28.586 & -30.909 & -30.305 \\
\hline 1325 & -30.0 .3 & -24.522 & -25.500 & -26.033 \\
\hline $12 \geq 2$ & -25.006 & -20.458 & -22.036 & -21.645 \\
\hline 1727 & -20.017 & -16.395 & -17.681 & $-17.35 i$ \\
\hline 1928 & -14.985 & -12.295 & -13.259 & -13.030 \\
\hline 1929 & -9.981 & -8.188 & -8.341 & -8.606 \\
\hline 1737 & $-4.90 ?$ & -4.085 & -4.413 & -4.344 \\
\hline 11.31 & 0.000 & 0.000 & 0.000 & 0.000 \\
\hline 1.732 & 5.018 & 4.032 & 4.403 & 4.353 \\
\hline 1,133 & 10.061 & 8.185 & 8.817 & 3.704 \\
\hline 1.734 & 15.005 & 12.248 & 13.228 & $13 . c 45$ \\
\hline 1735 & 20.101 & 16.335 & 17.653 & 17.395 \\
\hline 1934 & 25.128 & 20.415 & 22.064 & 21.747 \\
\hline $143 ?$ & $30 \cdot 1 \% 4$ & 24.493 & 26.479 & 26.095 \\
\hline $1 \times 3$ is & 35.152 & 2.3 .578 & 30.372 & 30.415 \\
\hline $1: 34$ & 40.160 & 32.659 & 35.273 & 34.746 \\
\hline$(74,1)$ & 45.171 & 36.722 & 39.635 & 39.068 \\
\hline 1961 & 50.163 & 40.794 & 44.077 & 43.365 \\
\hline 1442 & 55.132 & 44.834 & 48.450 & 47.695 \\
\hline 1443 & 60.103 & 48.862 & 52.829 & $N . A$. \\
\hline 1144 & 65.079 & 52.899 & 57.249 & A.A. \\
\hline 1.145 & 70.045 & 56.915 & 61.612 & A.A. \\
\hline 1745 & 74.977 & 60.949 & 66.041 & A.A. \\
\hline
\end{tabular}


1. The general fertility rate is defined as the ratio of the number of births to the number of women 15-44, multiplied by 1,000 .

2. The data in Graph 1 are from Vital Statistics of the United States: 1968, Volume 1, Natality.

3. The increases in fertility from 1968 to 1969 and from 1969 to 1970 show up not only in the crude birth rate, but in the general fertility rate as well. The following pattern of recent fertility variations has been drawn from various issues of the Monthly Vital Statistics Report, a publication of the U.S. Department of Health, Education and Welfare.

\begin{tabular}{ccc} 
Year & Crude Birth Rate & General Fertilit \\
\cline { 2 - 3 } 1967 & 17.8 & 87.8 \\
1968 & 17,5 & 84,8 \\
1969 & 17,8 & 86,5 \\
1970 & 18,2 & 87,6 \\
1971 & 17,3 & 82,3 \\
1972 & 15,6 & 73,4
\end{tabular}

Source: U. S. Department of Health, Education and Welfare, Public Health Service, Health Records Administration, Monthly Vital Statistics Report.

Issues: Vol. 16, No. 13, July 26, 1968; Vol, 17, No, 13, August 15, 1969; Vol, 20, No. 13, August 30, 1972; Vo1, 21, No, 13, June 27, 1973; Vol. 22, No. 7, Supplement, October 2, 1973. It is possible that more disaggregated fertility measures such as age- and parity-specific birth probabilities do not show the 1969 and 1970 increases.

4. See the March/April 1973 Supplement to the Journal of Political Economy, particularly Willis (1973). 


\section{Eootnotes (continued)}

5. By "native" white women, we mean women born in the United States,

6. Data for the years 1920 through 1949 appear in Whelpton (1954), Table E. Data for 1950 can be found In Table G.

7. See Whelpton and Campbell (1960). Although birth probabilities were not published in that report, it laid the foundation for the birth probabilities which were subsequently published in yarious issues of Vital Statistics of the United States.

8. Our estimates are created with a methodology which differs from the original Whelpton procedures in a large number of relatively unimportant ways. For example, our estimates explicitly take twinning into account, whereas the Whelpton birth probabilities do not, However, there is one quite important difference in our methods. We have taken into consideration the fact that women who have had a child are not immediately at risk of bearing another child. The Whelpton methodology makes no distinction ebtween women who have had births within the previous year and those who have not. See Sanderson (1974) Appendix A for a more comprehensive discussion of the methodology used in creating the current estimates as well as the methodologles used by others.

9. We have not re-estimated birth probabilities for cohorts born in the nineteenth century. There are a number of difficulty technical problems involved in doing this which seem to make this data considerably less rellable than the data for twentieth century birth cohorts. Our estimates stop in 1966 because this is the latest date 
Footnotes (continued)

9. (cont'd.)

for which birth data on native white women are published in the needed detail, Age- and parity-specific birth data for all white women have, at this writing, been published only through 1968 , Thus even adjusting the white data as best we could would only give us two extra years of data.

10. For example, see Keyfitz (1971).

11. The birth probabilities presented in this paper have been computed on the assumption that, neglecting twinning, a woman must wait at least a year between births. While twelve months may be slightly longer than the average period of gestation and pst-partum amenorhia, using that figure iads in our computations without doing much violence to reality.

12. Throughout this paper, we shall use the phrase "baby boom peak" to refer to the highest birth probability in a series during the period 1950 to 1966 .

13. These birth probability series are time series of age- and parityspecific birth probabilities. Thus the 30 first order birth probability series referred to in Table 1 are for women from age 15 to age 44. We assume, following Whelpton, that 15 year old women do not have second births (except for twins) and therefore there are only 29 series for second births. It is these minimum age assumptions which cause the number of series to decrease as the birth order increases. 
Footnotes (continued)

14. By coherent set of birth probabilities we simply mean a set of birth probability series with adjacent ages. Thus the birth probabllity series of women 20,21 , and 22 would be coherent, in this sense, but not those of women 31,35 , and 39 ,

15. The third order birth probabilfty peak for 40 to 44 year old women occurred in 1954, 1955, and 1956, but the fall from 1956 to 1957 Is so small that for practical purposes 1957 may also be considered a peak year.

16. This article can be found in Easterlin (1968), Chapter 3,

17. Briefly, this hypothesis suggests that adolescents' tastes and hence ultimately their adult fert1lity are affected by their parents' standard of 11ving.

18. Above, we have defined $m$ as that cohort which is of age $f$ in year $k$. Since m and $n$ must differ, it will never be possible to observe women of cohort $n$ at age $j$ in year $k$.

19. See Coale and Zelntk (1963), page 22, 


\section{REFERENCES}

Becker, Gary S., "A Theory of the Allocation of Time," Economic Journal, 75 (September 1965), 493-517.

Coale, Ansley J. and Melvin Zelnik, New Estimates of Fertility and Population in the United States, Princeton, Princeton University Press, 1963.

Easterlin, Richard A., Population, Labor Force and Long Swings in Economic Growth: The American Experience, General Series 86, New York, National Bureau of Economic Research, 1968.

Keyfitz, Nathan, "How Birth Control Affects Births," Social Biology, 18, No. 2 (June 1971), 109-21.

Michael, Robert T., "Education and the Derived Demand for Children," Journal of Political Economy, Vo1. 81, No. 2, Part II, March/April 1973, S128-S164.

Sanderson, Warren C., Toward an Economc Understanding of the Fertility of American Women in the Twentieth Century, Ph.D. dissertation, Stanford University, pending, 1974 .

United Staes Department of Health, Education and Welfare, Public Health Service, Vital Statistics of the United States, varlous years, Washington, D. C., U.S. Government Printing Office.

Whelpton, Pascal K., Cohort Fertility, Princeton, Princeton University Press, 1954 .

Whelpton, Pascal K., and Arthur A. Campbell, "Fertility Tables for Birth Cohorts of American Women," Vital Statistics - Special Reports, Vo1. 51, No. 1, January 1960, National office of Vital Statistics, Public Health Service, Washington, D. C. 